\title{
Oil volatility, oil and gas firms and portfolio diversification*
}

\author{
Nikolaos Antonakakis ${ }^{\dagger, \ddagger}$, Juncal Cunado ${ }^{\S}$, George Filis ${ }^{\Uparrow}$, David Gabauer ${ }^{\|}$, and Fernando \\ Perez de Gracia ${ }^{\S}$ \\ ${ }^{\dagger}$ Economics and Finance Subject Group, University of Portsmouth, Portsmouth Business School, \\ Portland Street, Portsmouth, PO1 3DE, United Kingdom. Tel: +44 (0)23 9284 4261. Email: \\ nikolaos.antonakakis@port.ac.uk \\ ${ }^{\ddagger}$ Department of Business and Management, Webster Vienna Private University, Praterstrasse 23, 1020, \\ Vienna, Austria. Tel: +43-1-2699293-4373. Email: nikolaos.antonakakis@webster.ac.at \\ $\S$ University of Navarra, Department of Economics, Pamplona 31080, Spain. Email: jcunado@unav.es, \\ fgracia@unav.es \\ "Department of Accounting, Finance and Economics, Bournemouth University, 89 Holdenhurst Road, \\ Executive Business Centre, BH8 8EB, Bournemouth, United Kingdom. Email: \\ gfilis@bournemouth.ac.uk \\ ॥ Johannes Kepler University, Department of Economics, Altenbergerstrae 69, 4040, Linz, Austria. \\ Email: david.gabauer@hotmail.com
}

January 28, 2018

\begin{abstract}
This paper investigates the volatility spillovers and co-movements among oil prices and stock prices of major oil and gas corporations over the period between 18th June 2001 and 1st February 2016. To do so, we use the spillover index approach by Diebold and Yilmaz $(2009,2012,2014,2015)$ and the dynamic correlation coefficient model of Engle (2002) so as to identify the transmission mechanisms of volatility shocks and the contagion of volatility among oil prices and stock prices of oil and gas companies, respectively. Given that volatility transmission across oil and major oil and gas corporations is important for portfolio diversification and risk management, we also examine optimal weights and hedge ratios among the aforementioned series. Our results point to the existence of significant volatility spillover effects among oil and oil and gas companies' stock volatility. However, the spillover is usually unidirectional from oil and gas companies' stock volatility to oil volatility, with BP, CHEVRON, EXXON, SHELL and TOTAL being the major net transmitters of volatility to oil markets. Conditional correlations are positive and time-varying, with those between each of the aforementioned companies and oil being the highest. Finally, the diversification benefits and hedging effectiveness based on our results are discussed.
\end{abstract}

Keywords: Oil prices, oil and gas corporations, volatility spillovers, volatility co-movement, hedging, portfolio weights

JEL codes: C32, F3, G12, Q43

* Juncal Cunado and Fernando Perez de Gracia acknowledge financial support from the Spanish Ministry of Economics and Competitiveness through project ECO-2014-55496R. George Filis acknowledges the support of the European Union's Horizon 2020 research and innovation programme, which has funded them under the Marie Sklodowska-Curie grant agreement No 658494. 


\section{Introduction}

Oil prices experienced a huge drop over the period 2014-2015. For example, the cost of a barrel of West Texas Intermediate crude oil fell by $75 \%$ (from $\$ 107.3$ to $\$ 26.68$ ) between the 20th of June, 2014, and the 20th of January, 2016. At the same time, this volatile behaviour of oil prices resulted in a strong hit to the revenues of oil and gas industry (Wall Street Journal, 2016). Furthermore, Britain's BP Upstream segment reported an underlying pre-tax replacement cost loss of $\$ 0.7$ billion in the 4 th quarter of the year 2015 compared with a profit of $\$ 2.2$ billion a year earlier (BP, 2016). In addition, stock prices of the oil and gas corporations also exhibited a significantly increased volatility and decline during 2015. Indicatively, BP's and ENI's share prices fell by $35 \%$ and 39\%, respectively, between January of 2014 and December of 2015 . Oil and gas companies are faced with "dark ages" as recently pointed out by The Economist (2016) with significant cuts in jobs, cost and capital spending. In addition, the recent decline in oil prices also generated a spillover impact on countries and sectors dependent on oil and other commodities (IMF, 2015; Husain et al., 2015).

To that end, this study investigates the volatility spillovers and volatility co-movements among oil prices and major oil and gas corporations' stock prices over the period between 18th June 2001 and 1st February 2016. The spillover index approach by Diebold and Yilmaz $(2009,2012,2014,2015)$ and the dynamic conditional correlation (DCC) model of Engle (2002) are employed to identify the transmission mechanism of volatility shocks and the contagion of volatility among oil prices and stock prices of oil and gas companies.

This paper extends the previous literature in several ways. First, to the best of our knowledge, this is the first empirical paper that examines the volatility relationship between oil price and stock prices using firm-level data of oil and gas corporations.

Studies recently examine the interaction between oil prices and stock markets volatility spillover effects (see, for example, Malik and Hammoudeh, 2007; Malik and Ewing, 2009; Arouri et al., 2011a,b, 2012; Sadorsky, 2012, among others), nevertheless, the analysis is performed at an aggregate level. Even more, most of the previous studies focus on the relationship between oil prices and aggregate stock returns (see, for example, the initial contributions on the topic by Kling, 1985; Jones and Kaul, 1996). ${ }^{1}$ Some additional empirical evidence focuses on the links between oil prices and stock returns using data of sectorial indices (see, for example, Hammoudeh et al., 2004; Hammoudeh and Li, 2005; Elyasiani et al., 2011; Scholtens and Yurtsever,

\footnotetext{
${ }^{1}$ Additional related references but not exclusive are Sadorsky (1999), Park and Ratti (2008), Broadstock and Filis (2014), Cunado and Perez de Gracia (2014) and Degiannakis et al. (2014) among many others.
} 
2012; Degiannakis et al., 2013; Broadstock and Filis, 2014; Caporale et al., 2015) while only a few papers specifically analyse the stock returns of oil and gas corporations (see, for example, Sadorsky, 2001; Lanza et al., 2005; Giovannini et al., 2006; Chang et al., 2009).

It is important to highlight, though, that aggregate or sectorial analyses may mask the heterogeneity that can be observed when considering firm-level approaches. We emphasize that an aggregate analysis is not particularly useful for international portfolio diversification and risk management analysis, as portfolio managers and investors primarily are interested in firm-level investment choices.

Furthermore, given the fact that the use of fixed-parameter models may mask the heterogeneity of the oil-stock relationship over time, some authors examine the time-varying relationship between oil and stock market returns. Nevertheless, the focus is either on aggregate stock market data or industrial sectors (see, among others, Choi and Hammoudeh, 2010; Filis et al., 2011; Broadstock et al., 2012; Chang et al., 2013; Degiannakis et al., 2013; Antonakakis and Filis, 2013; Broadstock and Filis, 2014; Filis, 2014). Overall, despite the ample evidence on the relationship between oil price and stock returns, the focus is still primarily on aggregate or sectorial indices. It is rather interesting that until very recently, the literature had ignored the use of firm-level data to examine the aforementioned relationship. Recent studies include Boyer and Filion (2007), Sadorsky (2008), Narayan and Sharma (2011) and Phan et al. (2016), although their analyses is only on returns rather than volatilities.

Second, our dataset includes time series data of daily stock prices of the world's largest oil and gas companies, over the period 2001-2016. Our sample period allows us compare their evolution among three different sub-periods: i) pre, ii) during and iii) after the 2007-09 financial crisis. For example, previous studies, such as Arouri et al. (2011b), consider shorter sample periods and take into account two sub-periods, the tranquil period (June 7, 2005 to June 29, 2007) and the crisis period (July 2, 2007 to February 21, 2010).

Third, and more importantly, our empirical approach also explores the diversification and hedging effectiveness between different hedging strategies. For example, previous studies, such as Arouri et al. (2011a,b, 2012) and Sadorsky (2012), take also into account a portfolio management with oil-risk hedging strategies.

The results of our empirical analysis can be summarised as follows. First, the proposed DCC model to study volatility co-movements suggests that correlations between the volatilities of WTI and each of the oil and gas companies are time-varying and reach a peak during the 20072009 financial crisis, although several other company-specific peaks are also identified during our 
sample period. Second, when the generalized version of the spillover index of Diebold and Yilmaz $(2012,2014,2015)$ is used to examine the volatility spillovers of major oil companies' stock prices and oil prices, the results suggest that the WTI volatility is actually impacted by the firm level volatility rather than the other way around. In addition, we also detect that the firms that exert the highest impact to WTI are BP, CHEVRON, ENI, SHELL, STATOIL and TOTAL. Third, we study whether different optimal diversification strategies exist in the pre-, during and postfinancial crisis period. The evidence supports that hedge ratios are volatile over time reaching a peak during the 2007-2009 financial crisis, although this is not the case for the WTI/ENI and WTI/PETROBRAS hedge ratios, which reach their peak in the post-financial crisis period. Finally, we show that the optimal portfolio weights strategy is more effective, compared to the optimal hedge ratio strategy, in terms of offering greater risk reduction opportunities.

The remainder of the paper is structured as follows. Section 2 describes the related literature review on volatility spillovers and co-movements. Section 3 discusses the methodology and describes the dataset. The empirical results are presented in Section 4. Finally, Section 5 discusses the main results and concludes this study.

\section{Literature review}

A large number of studies have already analyzed the nexus between oil prices and stock prices returns (see, for example, the recent papers by Broadstock and Filis, 2014; Degiannakis et al., 2014, and references therein), while only very recently authors focus on the volatility interrelationships between oil and stock market returns, mainly in terms of volatility spillovers (see, for example, Malik and Hammoudeh, 2007; Malik and Ewing, 2009; Arouri et al., 2011a,b, 2012; Sadorsky, 2012; Awartani and Maghyereh, 2013; Chang et al., 2013; Khalfaoui et al., 2015; Ewing and Malik, 2016; Maghyereh et al., 2016; Phan et al., 2016). In order to model volatility interrelationships, the recent literature on oil and stock returns has used alternative methodological approaches, such as the DCC model of Engle (2002), BEKK-GARCH model of Engle and Kroner (1995), multivariate vector autoregressive-generalized autoregressive conditional heteroscedasticity (VAR-GARCH) model developed by Ling and McAleer (2003), exponential generalized autoregressive conditional heteroskedasticity (also known as EGARCH) and a volatility spillover measure based on forecast error variance decompositions from vector autoregressions developed by Diebold and Yilmaz (2009, 2012, 2014, 2015).

Even more, the majority of the studies that investigate the oil-stock market volatility re- 
lationship, primarily consider aggregate stock market indices. For example, Malik and Hammoudeh (2007) examine the volatility transmission mechanisms among the US equity market, the global crude oil market, and the equity markets of the major oil rich Gulf countries (namely Saudi Arabia, Kuwait, and Bahrain), using daily returns from February 14, 1994 to December 25, 2001. They show that significant interaction exists between the second moments of the US equity and the global oil markets. In addition, Arouri et al. (2011b) investigate the return links and volatility transmission between oil and stock markets in the six member countries of the Gulf Cooperation Council (namely Bahrain, Kuwait, Oman, Qatar, Saudi Arabia, and the United Arab Emirates) over the period from June 7, 2005 to February 21, 2010. The results point to the existence of significant shock and volatility spillovers between oil and stock markets in most of the cases, especially over the crisis sub-period. Similar results are reported by Awartani and Maghyereh (2013), who investigate the dynamic spillovers of volatility between oil and equity indices in the Gulf Cooperation Council Countries using weekly data from the 2nd of January 2004 to the 30th of March 2012. They find that the information flow from oil volatility to the GCC stock markets' volatility is important, while the flow in the opposite direction is marginal. These patterns have intensified following the 2007-09 financial crisis, where net spillovers from the oil price volatility to the GCC stock markets volatility have increased significantly.

Studies focusing on the US market also report significant spillover effects between oil and stock market volatility. In particular, Ewing and Malik (2016) analyse volatility dynamics of oil prices and S\&P500 index using daily returns from July 1, 1996 to June 30, 2013 and taking into account endogenously determined structural breaks. Their results show a significant direct and indirect transmission effect of volatilities between oil and the US stock market. In addition, Phan et al. (2016) investigate the price volatility interaction between the crude oil and the US stock market (i.e., the E-mini S\&P500 index futures and the E-mini NASDAQ index futures) using 5-minutes data for the period 2 January 2009 to 31 December 2012. Their findings suggest a positive contemporaneous relationship between bid-ask spread, trading volume, and price volatility.

Other studies consider multiple major global stock markets. Khalfaoui et al. (2015), for instance, examine volatility spillovers of oil and stock market prices using daily data of the G7 stock markets from June 2, 2003 to February 7, 2012. They find strong evidence of significant volatility spillovers between oil and stock market volatility. In a recent study, Maghyereh et al. (2016) investigate the connectedness between oil implied volatility and equity indices' implied volatility in eleven major equity markets (i.e., the US, Canada, the UK, India, Mexico, Japan, 
Sweden, Russia, South Africa, Germany and Switzerland) using daily observations from the 3rd of March 2008 to the 3rd of February 2015. Their results support that the connectedness between oil and equity volatility is established by the bi-directional information spillovers between the two markets. However, they find that the bulk of association is largely dominated by the transmissions from the oil market to equity markets and not the other way around. The pattern of transmissions is varying over the sample period; however, most of the linkages between oil and equities are established from the mid-2009 to the mid-2012, which is a period that witnessed the start of global, albeit sluggish, recovery. Boldanov et al. (2016) also show that the relationship between oil and stock market volatilities is time-varying, although they report that volatility correlations are intensified during the 2007-09 financial crisis. Importantly, they suggest that there is heterogeneity in these correlations between the oil-importing and oil-exporting economies.

On the other hand, Chang et al. (2013) do not offer support to the aforementioned findings. They use daily data from January 2, 1998 to November 4, 2009 of the crude oil spot, forward and futures prices from the WTI and Brent markets, and the FTSE100, NYSE, Dow Jones and S\&P500 stock index to investigate the conditional correlations and volatility spillovers between the crude oil and financial markets. Their results show little evidence of volatility spillovers between the crude oil and financial markets.

Given that aggregate stock market indices may mask the heterogeneity of responses to oil price volatility from the different sectors, some authors considered the relationship between oil and stock market volatility at sectorial level. Malik and Ewing (2009), for instance, examine the transmission of volatility and shocks between oil prices and five US major market sectors (i.e., financials, industrials, consumer services, health care, and technology) using weekly data from January 1, 1992 to April 30, 2008. Their results provide evidence of significant volatility transmission between the oil market and some of the examined sectors. Arouri et al. (2011a) also examine the extent of volatility transmission between oil and stock markets in Europe and the US, at the sectorial level (i.e., automobile \& parts, financials, industrials, basic materials, technology, telecommunications, and utilities), using weekly data from January 1, 1998 to December 31, 2009. Their results show significant volatility interaction between oil and stock market sectors, although for Europe, the transmission of volatility is much more apparent from oil to stocks than from stocks to oil. In a related study, Arouri et al. (2012) investigate the volatility spillovers between oil price and sector stock prices in Europe collecting data for the Dow Jones Stoxx Europe 600 index and seven DJ Stoxx sector indices (i.e., automobile \& parts, financials, industrials, basic materials, technology, telecommunications, and utilities) over the 
period from January 1, 1998 to December 31, 2009. Their findings show significant volatility spillovers between oil price and sector stock returns.

Sadorsky (2012), on the other hand, analyzes the volatility spillovers between oil prices and the US stock prices of clean energy companies and technology companies only, using daily data from January 1, 2001 to December 31, 2010. He employs various multivariate GARCH models (i.e., BEKK, Constant Conditional Correlation (CCC), and DCC) and shows that the stock prices of clean energy companies are more highly correlated with technology stock price volatility than with oil price volatility.

In the context of the previous literature, this paper specifically focuses on volatility spillovers and volatility co-movements among oil prices and major oil and gas corporations' stock prices during the period between the 18th June 2001 to 1st February 2016. The only two studies that are closer to this, are performed by Boldanov et al. (2016) and Maghyereh et al. (2016) who examine the relationship between stock market and oil price volatilities, although yet again at the aggregate level. As aforementioned, though, in the introduction of our paper, both aggregate and sectorial indices may mask the heterogeneity at the firm level. Such heterogeneity is important as international portfolio diversification strategies and risk management analyses are mainly performed at firm-level rather than at more aggregated levels.

\section{Dataset and methodology}

\subsection{Dataset}

The choice of our oil and gas companies' dataset is based on the satisfaction of the following two criteria. First, they need to be among the largest 25 oil and gas firm of the world and listed in the largest stock markets. This criterion safeguards that the chosen firms will be among the largest players in the market and their stocks will be highly liquid. Second, they need to be listed for at least 15 years so to allow the estimation of volatility spillovers in the pre-, during and postfinancial crisis period (as our adopted approaches are data demanding). Given these criteria, our final dataset includes 12 of the 25 largest world oil and gas companies. Indicatively, these firms had annual revenues in 2014 greater than US\$82 billion. We also use data of crude oil WTI cushing US\$/BBL. All series are expressed in US dollars. Data are obtained from Datastream database and cover the period 18th June 2001 to 1st February 2016, a total of 3815 observations. ${ }^{2}$ The selected oil and gas corporations are the following: BP (BP), CHEVRON Corporation

\footnotetext{
${ }^{2}$ The starting period of our sample is dictated purely by data availability.
} 
(CHEVRON), China National Petroleum Corporation (CNCP), Eni SpA (ENI), Exxon Mobil Corporation (EXXON), Lukoil (LUKOIL), Petroleo Brasileiro SA (PETROBRAS), Royal Dutch Shell (SHELL), Sinopec, also China Petroleum \& Chemical Corporation (SINOPEC), Statoil ASA (STATOIL), Total SA (TOTAL) and Valero Energy Corporation (VALERO).

Following Forsberg and Ghysels (2007), Antonakakis and Kizys (2015) and Wang et al. (2016), we define the stock $i$ (oil) price volatility as the absolute return $V_{i t}=\left|\ln P_{i t}-\ln P_{i t-1}\right|$, where $P_{i t}$ is the daily closing value of the stock (oil) price on day $t .{ }^{3}$ Daily volatilities of our series are presented in Figure 1.

[Insert Figure 1 around here]

It is evident from Figure 1 that all oil and gas firms, as well as, WTI share some common peaks and troughs in their volatilities, with most striking the peaks during the 2007-09 financial crisis period, where most volatilities reached unprecedented levels. Interesting enough, BP's volatility reaches its highest peak in 2010, showing the impact that the Deepwater Horizon Oil Spill in Mexico had in its share price. In addition, CNPC's volatility also exhibits a significant peak during 2003, possibly as a result of the gas leak in Chongqing municipality in China. A final observation that is worth mentioning here is the relative higher volatility that SINOPEC exhibits compared to all other companies. Descriptive statistics of our data are presented in Table 1.

[Insert Table 1 around here]

\subsection{Empirical methodology}

Our empirical analysis consists of the following two steps. In the first step, we estimate the time-varying correlations between WTI and the oil and gas firms' volatilities, so as to assess the dynamic linkages between the aforementioned series, as well as, to use this information for the construction of the optimal diversification strategies. In the second step, we examine the volatility spillover effects among our series, in order to understand the transmission mechanism and contagion effects of volatility shocks.

\footnotetext{
${ }^{3}$ For a detailed discussion of the advantages of using absolute return as a measure of volatility see Forsberg and Ghysels (2007). We have, however, experimented with alternative measures of volatility, such as conditional volatility, and our results remained qualitatively very similar to those presented below. Results based on conditional volatility as a measure of volatility are available upon request from the authors.
} 


\subsubsection{Dynamic conditional correlation}

To examine the time-varying correlations in the volatilities of each of the major oil and gas companies' stock prices of and oil prices we employ the DCC model proposed by Engle (2002).

The DCC model of Engle (2002) is defined as:

$$
\begin{gathered}
r_{t}=\mu_{t}(\theta)+\epsilon_{t}, \quad \text { where } \epsilon_{t} \mid \Omega_{t-1} \sim N\left(0, H_{t}\right) \\
\epsilon_{t}=H_{t}^{1 / 2} u_{t}, \quad \text { where } u_{t} \sim N(0, I) \\
H_{t}=D_{t} R_{t} D_{t}
\end{gathered}
$$

where $r_{t}=\left(r_{i t}, \ldots, r_{N t}\right)^{\prime}$ is a $N \times 1$ vector of volatilities (specifically, the WTI, BP, CHEVRON, CNPC, ENI, EXXON, LUKOIL, PETROBRAS, SHELL, SINOPEC, STATOIL, TOTAL and the VALERO volatilities, thus $\mathrm{N}=13) ; \mu_{t}(\theta)=\left(\mu_{i t}, \ldots, \mu_{N t}\right)^{\prime}$ is the conditional $13 \times 1$ mean vector of $r_{t}, H_{t}$ is the conditional covariance matrix, $D_{t}=\operatorname{diag}\left(h_{i i t}^{1 / 2}, \ldots, h_{N N t}^{1 / 2}\right)^{\prime}$ is a diagonal matrix of square root conditional variances, where $h_{i i t}$ can be defined as any univariate GARCH-type model, and $R_{t}$ is the $t \times\left(\frac{N(N-1)}{2}\right)$ matrix containing the time-varying conditional correlations defined as:

$$
R_{t}=\operatorname{diag}\left(q_{i i, t}^{-1 / 2}, \ldots, q_{N N, t}^{-1 / 2}\right) Q_{t} \operatorname{diag}\left(q_{i i, t}^{-1 / 2}, \ldots, q_{N N, t}^{-1 / 2}\right) \quad \text { or } \quad \rho_{i j, t}=\rho_{j i, t}=\frac{q_{i j, t}}{\sqrt{q_{i i, t} q_{j j, t}}}
$$

where $Q_{t}=\left(q_{i j, t}\right)$ is a $N \times N$ symmetric positive definite matrix given by:

$$
Q_{t}=(1-\alpha-\beta) \bar{Q}+\alpha u_{t-1} u_{t-1}^{\prime}+\beta Q_{t-1}
$$

where $u_{t}=\left(u_{1 t}, u_{2 t} \ldots u_{N t}\right)^{\prime}$ is the $N \times 1$ vector of standardized residuals, $\bar{Q}$ is the $N \times N$ unconditional variance matrix of $u_{t}$, and $\alpha$ and $\beta$ are nonnegative scalar parameters satisfying $\alpha+\beta<1$.

The DCC model is estimated using a two-step procedure. In the first step, the individual conditional variances are specified as univariate GARCH processes and in the second step the standardized residuals from the first step are used to construct the conditional correlation matrix. ${ }^{4}$ Moroever, the DCC model is estimated using the Quasi-Maximum Likelihood (QML) estimator under a multivariate Student distribution (see Harvey et al., 1992; Fiorentini et al., 2003). The multivariate Student distribution is applied as the normality assumption of the

\footnotetext{
${ }^{4}$ This method overcomes certain numerical difficulties often arising in estimating multivariate GARCH models (such as the estimation of many parameters simultaneously, which might not ensure positive definiteness of the covariance matrix), and it also enables the estimation of time-varying volatilities, covariances and correlations.
} 
innovations is rejected for each volatility series.

\subsubsection{Volatility spillover index}

To examine spillovers in the volatility of major oil companies' stock prices and oil prices, we apply the generalized version of the spillover index in Diebold and Yilmaz (2012, 2014, 2015), originally proposed by Diebold and Yilmaz (2009), and which builds on the seminal work on vector autoregressive (VAR) models by Sims (1980) and the notion of variance decompositions. The generalized version overcomes the shortcomings of potentially order-dependent results due to Cholesky factor orthogonalization in Diebold and Yilmaz (2009). Moreover, using rollingwindow estimation, the dynamic evolution of the importance of spillover effects can be assessed and illustrated using spillover plots.

Starting point for the analysis is the following $K^{\text {th }}$ order, $N$ variable VAR

$$
y_{t}=\sum_{k=1}^{K} \Theta_{k} y_{t-k}+\varepsilon_{t}
$$

where $y_{t}=\left(y_{1 t}, y_{2 t}, \ldots, y_{N t}\right)$ is a vector of endogenous variables, comprising $n=1, \ldots, N(13)$ observations on the volatility of major oil companies' stock prices and oil prices at day $t ; \Theta_{k}, k=$ $1, \ldots, K$, are $N \times N$ parameter matrices and $\varepsilon_{t} \sim(0, \Sigma)$ is vector of disturbances that are assumed to be independently (though not necessarily identically) distributed over time).

Key to the dynamics of the system is the moving average representation of equation 6 , which is given by $y_{t}=\sum_{p=0}^{\infty} A_{p} \varepsilon_{t-p}$, where the $N \times N$ coefficient matrices $A_{p}$ are recursively defined as follows: $A_{p}=\Theta_{1} A_{p-1}+\Theta_{2} A_{p-2}+\ldots+\Theta_{p} A_{p-l}$, where $A_{0}$ is the $N \times N$ identity matrix and $A_{p}=0$ for $p<0$.

Given that any particular ordering of the variables in our VAR model (that covers 13 variables and a time period that includes the recent 2007-09 financial crisis) is hard to justify, we use the variant of the spillover index in Diebold and Yilmaz (2012, 2014, 2015), which is based on the generalized VAR framework (Koop et al., 1996; Pesaran and Shin, 1998), in which forecast error variance decompositions are invariant to the ordering of the variables. Of course, this has advantages and drawbacks. Given our goal to assess the magnitude of volatility spillovers (as determinants of (the share of) variables' forecast error variances) rather than identifying the causal effects of structural shocks, this appears to be the preferred choice in the present context. ${ }^{5}$

\footnotetext{
${ }^{5}$ However, we explore the robustness of our results by using Cholesky factorization with alternative orderings of the variables, as discussed below, and our results remain very similar.
} 
In the generalized VAR framework, the $H$-step-ahead forecast error variance decomposition is

$$
\phi_{i j}(H)=\frac{\sigma_{j j}^{-1} \sum_{h=0}^{H-1}\left(e_{i}^{\prime} A_{h} \Sigma e_{j}\right)^{2}}{\sum_{h=0}^{H-1}\left(e_{i}^{\prime} A_{h} \Sigma A_{h}^{\prime} e_{i}\right)},
$$

where $\Sigma$ is the (estimated) variance matrix of the error vector $\varepsilon, \sigma_{j j}$ the (estimated) standard deviation of the error term for the volatility of variable $j$, and $e_{i}$ a selection vector with 1 as the $i^{t h}$ element and zeros otherwise. This yields a $13 \times 13$ matrix $\phi(H)=\left[\phi_{i j}(H)\right]_{i, j=1, \ldots 13}$, where each entry gives the contribution of variable $j$ to the forecast error variance of variable $i$ 's volatility. The main diagonal elements contains the (own) contributions of volatility shocks to variable $i$ to its own forecast error variance, the off-diagonal elements represent cross-market volatility spillovers, defined here as contributions of other variables $j$ to the forecast error variance of variable $i$.

Since the own and cross-variable variance contribution shares do not sum to 1 under the generalized decomposition, i.e., $\sum_{j=1}^{N} \phi_{i j}(H) \neq 1$, each entry of the variance decomposition matrix is normalized by its row sum, such that

$$
\tilde{\phi}_{i j}(H)=\frac{\phi_{i j}(H)}{\sum_{j=1}^{N} \phi_{i j}(H)}
$$

with $\sum_{j=1}^{N} \tilde{\phi}_{i j}(H)=1$ and $\sum_{i, j=1}^{N} \tilde{\phi}_{i j}(H)=N$ by construction.

This ultimately allows to define a total spillover index, which is given by the following:

$$
T S(H)=\frac{\sum_{i, j=1, i \neq j}^{N} \tilde{\phi}_{i j}(H)}{\sum_{i, j=1}^{N} \tilde{\phi}_{i j}(H)} \times 100=\frac{\sum_{i, j=1, i \neq j}^{N} \tilde{\phi}_{i j}(H)}{N} \times 100
$$

which measures, on average over all variables, the contribution of volatility spillovers from shocks to all (other) variables to the total forecast error variance.

This approach is quite flexible and allows to obtain a more differentiated picture by considering directional volatility spillovers: Specifically, the directional volatility spillovers received by variable $i$ from all other variables $j$ are defined as follows:

$$
D S_{i \leftarrow j}(H)=\frac{\sum_{j=1, j \neq i}^{N} \tilde{\phi}_{i j}(H)}{\sum_{i, j=1}^{N} \tilde{\phi}_{i j}(H)} \times 100=\frac{\sum_{j=1, j \neq i}^{N} \tilde{\phi}_{i j}(H)}{N} \times 100
$$

and the directional volatility spillovers transmitted by variable $i$ to all other variables $j$ as follows:

$$
D S_{i \rightarrow j}(H)=\frac{\sum_{j=1, j \neq i}^{N} \tilde{\phi}_{j i}(N)}{\sum_{i, j=1}^{N} \tilde{\phi}_{j i}(H)} \times 100=\frac{\sum_{j=1, j \neq i}^{N} \tilde{\phi}_{j i}(H)}{N} \times 100 .
$$

Notice that the set of directional volatility spillovers provides a decomposition of total volatility 
spillovers into those coming from (or to) a particular variable.

By subtracting equation (10) from equation (11) the net volatility spillovers from variable $i$ to all other variables $j$ are obtained as follows:

$$
N S_{i}(H)=D S_{i \rightarrow j}(H)-D S_{i \leftarrow j}(H),
$$

providing information on whether a market is a receiver or transmitter of volatility shocks in net terms. Put differently, equation (12) provides summary information about how much each variable's volatility contributes to the volatility in the other variables, in net terms.

Finally, the net pairwise volatility spillovers can be calculated as

$$
\begin{aligned}
N P S_{i j}(H) & =\left(\frac{\tilde{\phi}_{j i}(H)}{\sum_{i, m=1}^{N} \tilde{\phi}_{i m}(H)}-\frac{\tilde{\phi}_{i j}(H)}{\sum_{j, m=1}^{N} \tilde{\phi}_{j m}(H)}\right) \times 100 \\
& =\left(\frac{\tilde{\phi}_{j i}(H)-\tilde{\phi}_{i j}(H)}{N}\right) \times 100 .
\end{aligned}
$$

The net pairwise volatility spillovers between markets $i$ and $j$ is simply the difference between the gross volatility shocks transmitted from variable $i$ to variable $j$ and those transmitted from variable $j$ to variable $i$.

\section{Empirical results}

In the following subsections, we begin our analysis of the time-varying correlations among the volatilities of WTI and each of the oil and gas companies. We then proceed with analysis of volatility spillovers and the implications for portfolio diversification.

\subsection{Volatility co-movements}

Figure 2 presents the results of the time-varying correlations between the volatilities of WTI and each of the oil and gas companies obtained from the DCC model.

[Insert Figure 2 around here]

It is clear that the relationships are indeed time-varying, although the correlations do not enter into negative territory in any of the cases. More specifically, correlations fluctuate at as low as 0.05 (WTI/SINOPEC) to as high as 0.5 (WTI/CHEVRON). It is interesting to note, though, that we do not observe any correlations at the high end range (i.e., at 0.7 or higher). This is suggestive of the fact that a considerable part of the volatility fluctuations are not driven either from WTI or the oil and gas firms. 
Furthermore, correlation clustering is also evident as, for example, during the financial crisis of 2008-09 all correlation figures increased dramatically, whereas low correlations are reported during 2005. Parallel to this, it is important to note that for several cases we observe a new correlation level in the post-crisis period (e.g., for BP, CHEVRON, ENI, EXXON, LUKOIL, SHELL, STATOIL).

The aforementioned findings are rather interesting, given the fact that Boldanov et al. (2016) show in their analysis that volatility correlations between oil and stock markets such as US or China (among others in their sample) could reach the level of almost 1, especially during the 2007-09 financial crisis. In addition, their results reveal that volatility correlations are also negative; a finding that is observed during the 2004-2005 hurricane period and the 20112014 Middle East conflicts. These notable differences between Boldanov et al. (2016) and our study strengthens our initial argument that the disaggregated approach could provide additional insights regarding the volatility relationships between oil and stock prices.

A final important observation is that the lowest correlations are observed in the cases of CNPC, SINOPEC and VALERO, whereas the highest are shown in the cases of BP, CHEVRON, SHELL and STATOIL. The finding for SINOPEC and CNPC is rather unexpected, given the importance of these firms in the global oil and gas industry (they are the 2nd and 3rd largest firms in the world). However, a plausible explanation for this finding could be the fact that in the Shanghai stock exchange there is a daily price up/down limit of $10 \%$ for stocks, as also suggested by Broadstock and Filis (2014).

Overall, these findings suggest that it is important to examine the aforementioned relationship in a time-varying environment, given the rich information that it provides. Next, we focus on the volatility spillovers between each of the sample firms and WTI.

\subsection{Volatility spillovers}

We continue our analysis on the relationship between WTI and oil and gas companies' volatilities, by investigating their spillover effects. Table 2 presents the volatility spillovers table based on the full sample estimation.

[Insert Table 2 around here]

We notice that the total volatility spillover index is fairly high (69.82\%), indicating a high interdependence among volatilities. From the net spillover indices we also notice that WTI is not a net volatility transmitter but rather an net volatility receiver $(-26.12 \%)$, suggesting that 
WTI volatility is impacted by the oil and gas companies' volatilities. Furthermore, firm-wise, CHEVRON, SHELL and TOTAL are the main net volatility transmitters $(22.90 \%, 23.21 \%$ and $24.89 \%$, respectively) to all other firms, as well as, WTI. At the opposite side, CNPC, SINOPEC and VALERO are the main volatility receivers $(-17.45 \%,-23.28 \%$ and $-13.21 \%$, respectively). Despite the interesting results presented in Table 2, we should emphasise on the fact that these are the volatility spillovers based on the full sample estimation. Having, though, documented that the relationship between WTI and oil and gas firm-level volatilities is time-varying, it is more important to examine how these volatility spillover effects evolve over time.

Figure 3 presents the total volatility spillover index over the sample period based on 500-day rolling windows and 30-day-ahead forecast horizon. ${ }^{6}$ It is interesting to note that despite the fact that the static total spillover index is estimated to be $69.82 \%$, when we examine this index over time we are able to see that it actually fluctuates from about $35 \%$ to almost $90 \%$. This is another indication that a time-varying approach provides significantly more information for oil market stakeholders, compared to the static analysis.

\section{[Insert Figure 3 around here]}

We observe that the total volatility spillover index started to show an increasing pattern since 2005, before it reaches its peak towards the end of the 2007-09 financial crisis. Importantly, we show that the spillover effects did not fade out immediately after the end of the crisis but rather it persisted until mid-2010. A plausible explanation of such persistence can be found in the events that followed the 2007-09 financial crisis and created uncertainty in the oil market. Such events include the Deepwater Horizon oil spill in the Gulf of Mexico in April 2010, caused by a BP's oil rig. Furthermore, a second phase of high spillover effects of about $75 \%$ is observed during the period between the mid-2011 until 2014, before they collapse to below $40 \%$ at the end of 2014. These spillover effects reflect the uncertainty in the energy market due to the Arab spring in 2011, the Libyan political unrest and the turbulence in Bahrain, Egypt and Yemen, as well as, the Syrian civil war in the post-2011 period. In addition, since 2015, when oil prices fluctuated around the $\$ 50$, a third phase of increased spillover effects were evident. It is interesting to highlight that during the collapse of the oil price in 2014-2015, volatility spillovers reached their lowest level. This might be at odds with conventional wisdom, however, a recent study by Fantazzini (2016) suggests that there was a negative bubble in oil prices in 2014-2015,

\footnotetext{
${ }^{6}$ We have also explored the robustness of our results based on alternative rolling windows (i.e. 300-day, 400day, 600-day and 700-day) and forecast horizon (i.e. 20-day and 40-day ahead forecasts horizon) and the results, that are available from the authors upon request, are qualitatively very similar.
} 
which decreased them beyond the level justified by economic fundamentals and which might explain the low volatility spillovers.

We further analyse the link between WTI and oil and gas firms' volatilities by estimating the time-varying net pairwise spillover effects ${ }^{7}$. Using the latter, we can focus solely on the relationship between WTI and each of the firm-level volatility, so as to establish which variables mainly transmit (receive) volatility spillover effects in net terms. The results are shown in Figure 4.

\section{[Insert Figure 4 around here]}

Figure 4 suggests that WTI clearly receives more spillovers effects compared to those it transmits. We also note that net transmission of volatility spillovers towards WTI increases significantly during and post-financial crisis period. This is indicative of the fact that it is not the oil price volatility that tends to dictate the firm-level volatility, but the reverse. Such finding is not in line with the majority of the papers which suggest that oil market mainly exercises an impact on stock market behaviour. Previous related studies that also detected a bi-directional volatility transmission are Arouri et al. (2011a, 2012), Khalfaoui et al. (2015) and Maghyereh et al. (2016). Arouri et al. (2011a) find that the volatility cross effects run only from oil to stock sectors in Europe, whereas bilateral spillover effects are found in the United States. Their results suggest that the intensity of "oil to stock" volatility transmission varies from one industry to another. In a new paper, Arouri et al. (2012) detect that the oil-financials sector model shows that there are bi-directional shock transmissions. Similarly, Awartani and Maghyereh (2013) maintain that return and volatility transmissions are bi-directional, albeit asymmetric. Khalfaoui et al. (2015) also detect that the volatility transmission from the French stock market to WTI oil market is bidirectional at the medium term and long term horizons. In a recent research, Maghyereh et al. (2016) show that the transmission of information between oil implied volatility and equity implied volatilities is bi-directional and asymmetric. The fact that our findings do not corroborate those of the previous studies suggests that the disaggregated approach provides additional insights on volatility spillover effects.

Furthermore, we also note that events such as the EXXON nationalisation by Venezuela in 2007 did also increase the spillover effects from Exxon to WTI quite significantly compared to the level of the net pairwise spillovers between Exxon and WTI, of the previous years. Similarly,

\footnotetext{
${ }^{7}$ The directional spillover effects FROM each variable and $T O$ each variable, as well as, the net spillovers are available in Figures A.1, A.2 and A.3, respectively, in the Appendix.
} 
there is a peak in the net pairwise spillovers between WTI and PETROBRAS in 2014, which could be explained by the fact that PETROBRAS was involved on what was characterised at the time, as the largest corruption scandal in Brazil.

Overall, despite the fact that WTI seems to be at the receiving end of spillover effects, there are some exceptions. These are mainly in relation to CNPC and SINOPEC volatilities, were, admittedly, the net pairwise spillover effects between WTI volatility and the volatilities of the two Chinese firms are marginal for most of our sample period. We should reiterate here that these are also the firms that exhibit the lowest correlations with WTI. Another exception is the spillover effects from WTI to LUKOIL and PETROBRAS towards the end of the sample period.

In summary, our findings show that (i) WTI volatility is actually impacted by the firm level volatility and that (ii) the two Chinese oil and gas firms are not influencing either the volatilities of their competitors or of WTI. Finally, (iii) the firms that exert the highest impact to WTI are BP, CHEVRON, ENI, SHELL, STATOIL and TOTAL.

\subsection{Hedge ratios and portfolio weights}

In this section, we examine the implications of the aforementioned results for international portfolio diversification and risk management. As discussed above, the dynamic conditional correlation patterns of our series have indeed changed over the sample period of the analysis (that includes extreme economic periods, such as the 2007-09 financial crisis). This, therefore, begs the question of whether different optimal diversification strategies exist in the pre-, during and post-financial crisis period. Hence, in our analysis below, we distinguish for such differences among the aforementioned 3 sub-periods.

To construct the optimal hedge ratios, we assume that investors are taking a long position in the WTI or oil and gas company volatility when future volatility in either of the assets is expected to be higher compared to the current volatility level. A short position is expected to be taken when the future volatility is anticipated to decrease. Investors might be willing to hedge their long or short positions as a precautionary measure for adverse movements of volatility.

The conditional variance estimates can be used to construct hedge ratios and optimal portfolio weights (see, inter alia Kroner and Sultan, 1993; Kroner and Ng, 1998; Hammoudeh et al., 2010; Chang et al., 2011; Balcılar et al., 2016; Maghyereh et al., 2017) ${ }^{8}$. Specifically, a long position in WTI volatility (denoted as volatility $o$ ) can be hedged with a short position in one of

\footnotetext{
${ }^{8}$ We should highlight here that our analysis is ex-post rather than looking at the out-of-sample optimal hedge ratios and portfolio weights.
} 
the oil companies' stock price volatility (denoted as oil company volatility $c$ ). Then, the hedge ratio between WTI volatility $o$ and oil company's stock price volatility $c$ is

$$
\beta_{o c, t}=h_{o c, t} / h_{c c, t},
$$

where $h_{o c, t}$ is the conditional covariance of WTI volatility $o$ and oil company's stock price volatility $c$, and $h_{c c, t}$ the conditional variance of $c$ oil company's stock price volatility at time $t$. The optimal portfolio weights between $o$ and $c$ are then calculated as

$$
w_{o c, t}=\frac{h_{c c, t}-h_{o j, t}}{h_{o o, t}-2 h_{o c, t}+h_{c c, t}},
$$

with

$$
w_{o c, t}= \begin{cases}0, & \text { if } w_{o c, t}<0 \\ w_{o c, t}, & \text { if } 0 \leq w_{o c, t} \leq 1 \\ 1, & \text { if } w_{o c, t}>1\end{cases}
$$

where $w_{o c, t}$ is the weight of WTI volatility in a one dollar portfolio of WTI volatility $o$ and one of the oil companies' stock price volatility $c$ at time $t$. Thus, $1-w_{o c, t}$ is the weight of one of the oil companies' stock price volatility $c$ at time $t$ in the aforementioned portfolio.

The evolutions of the hedge ratios and portfolio weights, computed from the conditional variance parameter estimates of the aforementioned DCC model, are presented in Figures 5 and 6, while their summary statistics are reported in Table 3.

\section{[Insert Figure 5 around here] \\ [Insert Figure 6 around here] \\ [Insert Table 3 around here]}

According to Figure 5 hedge ratios are fairly volatile over time. Furthermore, it is clear that they reach a peak during the 2007-09 financial crisis, suggesting an increased hedging cost during that turbulent time due to the increased number of contracts required for the hedging strategy. Nevertheless this does not hold for all the hedge ratios, as indicatively, we notice that the WTI/ENI and WTI/PETROBRAS hedge ratios reach their peak in the post-financial crisis period. Furthermore, hedge ratios are significantly lower when we assume a long position in the WTI volatility, compared to these when a short position is taken in the WTI volatility. This is expected given the findings in Section 4.2, which showed that WTI is mainly impacted by the firm level volatility rather than the reverse. 
The dynamic portfolio weights are also extremely volatile, as shown in Figure 6, indicating that active portfolio management is required when investing in these volatilities. It is rather interesting that in some cases the optimal weights show a zero dollar investment in the WTI volatility, suggesting that the minimum-variance portfolio is achieved using a single-asset portfolio, composed by the volatility of an oil and gas company (as in the cases of BP, CHEVRON and EXXON).

Turning to panel A in Table 3, the average value of the hedge ratio between a long position in WTI volatility and short position in the oil and gas firm volatility ranged between 14 and 29 cents of the dollar, suggesting that the cheapest hedge for $\$ 1$ long position in WTI is obtained with EXXON (14 cents), whereas the most expensive with LUKOIL (29 cents). Thus, LUKOIL is the least useful firm to hedge against WTI volatility. We notice that average hedge ratios for $\$ 1$ long position in the WTI volatility do not change notably in the pre-, during and post-financial crisis periods, although hedging was cheaper in the pre-2007 period.

On the other hand, the hedging cost of a $\$ 1$ long position in firm-level volatility using a short position in the WTI volatility varies significantly. For instance, we need 17 cents of the dollar in WTI volatility to hedge against PETROBRAS volatility, whereas 45 cents of the dollar are required in WTI volatility to hedge against $\$ 1$ dollar in CHEVRON volatility. Once again, we do not observe any abrupt changes in these hedge ratios during the three sub-periods.

Turning to Panel B in Table 3, we report the summary statistics for portfolio weights. For instance, the average weight for the WTI/BP portfolio is 0.30 for the full sample period, indicating that for $1 \$$ portfolio, 30 cents should be invested in WTI and 70 cents in BP. For the majority of the portfolios, WTI volatility assumes the lowest weight, although this does not hold for the portfolios between WTI and CNPC, LUKOIL, PETROBRAS, SINOPEC and VALERO. As a final note we should reiterate that, although important, the average values do not provide the full picture, given the high volatility that is observed in both the hedge ratios and portfolio weights at all periods.

Finally, it is important to allow comparisons between these two hedging techniques and this is performed by means of hedging effectiveness. Hedging effectiveness is calculated as follows:

$$
\mathrm{HE}=\left[\frac{h_{o o, c c}-h_{\beta, w}}{h_{o o, c c}}\right]
$$

The $h_{o o, c c}$ denotes the variance of the unhedged position of either the WTI or a company's volatility, which is estimated from the DCC model. The $h_{\beta, w}$ refers to the hedged portfolio 
variance either from the optimal hedge ratio strategy or the optimal portfolio weights strategy.

The results for the hedging effectiveness of the optimal hedge ratio strategy is shown in Table 4, whereas Table 5 depicts the hedging effectiveness of the optimal portfolio weights strategy.

[Insert Table 4 around here]

[Insert Table 5 around here]

Table 4 reveals that, on average, the optimal hedge ratio strategy should not be preferred when WTI volatility is hedged with LUKOIL, PETROBRAS and SINOPEC, as well as, when BP, CHEVRON, ENI, EXXON, SHELL and TOTAL volatilities are hedged with WTI volatility. Overall, it is rather evident that the optimal hedge ratio has low hedging effectiveness, which amounts to a reduction of risk at the levels between $0 \%$ and $7.79 \%$.

By contrast, the optimal portfolio weights strategy (Table 5) is able to generate significant gains from risk reduction either compared to the unhedged position in an oil company's volatility or in WTI volatility. In particular, the highest hedging effectiveness for WTI volatility can be achieved by forming a portfolio with EXXON or CHEVRON, whereas SINOPEC and PETROBRAS volatility investors could form portfolios with WTI volatility in order to achieve the greatest hedging effectiveness. The latter findings are suggestive of the fact that the optimal weights strategy is, on average during our sample period, the most preferred hedging strategy.

\section{Conclusions}

This paper investigates the volatility spillovers and co-movements among oil prices and stock prices of major oil and gas corporations over the period between 18th June 2001 and 1st February 2016. To the best of our knowledge, this is the first empirical study that covers the volatility spillovers and co-movements using firm-level data from twelve oil and gas firm stock price data and the WTI oil prices.

Our main findings can be summarised as follows. First, the proposed DCC model to study volatility co-movements suggests a time-varying correlations between the volatilities of WTI and each of the oil and gas companies. The values of the time-varying correlations fluctuate at as low as 0.05 (WTI/SINOPEC) to as high as 0.5 (WTI/CHEVRON). More specifically, the dynamic conditional correlations between WTI volatility and oil companies' stock price volatility suggest that during the 2007-09 financial crisis all correlation figures increased dramatically, while lower correlations were found during 2005. These results are in line with Sadorsky (2012) and Boldanov 
et al. (2016), who find that dynamic conditional correlations between oil and stock prices reach their highest values in the fall of 2008 , coinciding with the global financial crisis.

Second, when we consider the spillover effect the evidence shows a high interdependence among volatilities. In particular, empirical evidence suggests that WTI volatility is actually impacted by the firm level volatility and the two Chinese oil and gas firms are not influencing either the volatilities of their competitors or this of WTI. In addition, we also detect that the firms that exert the highest impact to WTI are BP, CHEVRON, ENI, SHELL, STATOIL and TOTAL.

Third, we study whether different optimal diversification strategies exist in the pre-, during and post-financial crisis period. The evidence supports that hedge ratios are volatile over time reaching a peak during the 2007-09 financial crisis except the WTI/ENI and WTI/PETROBRAS hedge ratios that reach their peak in the post-financial crisis period. The average hedge ratios in the WTI volatility do not change notably in the pre-, during and post-financial crisis periods.

Finally, we show that the optimal portfolio weights strategy is more effective in offering risk reduction, compared to the optimal hedge ratio strategy. The optimal portfolio weights offer significant diversification opportunities in relation to an unhedged position in either the WTI volatility or the volatility of an oil company.

The fact that we report significant different findings among each of the oil and gas companies, in relation to portfolio diversification and risk management, provides evidence of the value added of the firm-level approach compared to an aggregate analysis. For example, the results suggest that the average value of the hedge ratio between a long position in WTI volatility and a short position in the oil and gas firm volatility ranged between 14 cents of a dollar for EXXON and, twice that value, 29 cents, for LUKOIL. Even more, we show that for certain oil and gas companies, the optimal hedge ratio strategy is not effective to reduce the level of risk.

Overall, our empirical results point to the existence of volatility spillovers and co-movements among oil prices and stock prices of oil and gas corporations. These results open the avenue for further study in out-of-sample forecasting optimal weights and hedge ratios. Further studies should also allow the inclusion of the potential common drivers of stock and oil prices and examine how these could impact the hedging effectiveness of risk management strategies. These results are specifically important for investors who are interested in oil and gas corporations and oil market. 


\section{Acknowledgements}

We would like to thank the editor (Richard S.J. Tol) and two anonymous referees for their invaluable comments and suggestions on a previous version of this paper. Juncal Cunado and Fernando Perez de Gracia acknowledge financial support from the Spanish Ministry of Economics and Competitiveness through project ECO-2014-55496R. George Filis acknowledges the support of the European Union's Horizon 2020 research and innovation programme, which has funded them under the Marie Sklodowska-Curie grant agreement No 658494. The usual disclaimer applies. 


\section{References}

Antonakakis, N., Filis, G., 2013. Oil prices and stock market correlation: a time-varying approach. International Journal of Energy and Statistics 1 (01), 17-29.

Antonakakis, N., Kizys, R., 2015. Dynamic Spillovers between Commodity and Currency Markets. International Review of Financial Analysis 41, 303-319.

Arouri, M. E. H., Jouini, J., Nguyen, D. K., 2011a. Volatility Spillovers between Oil Prices and Stock Sector Returns: Implications for Portfolio Management. Journal of International Money and Finance 30 (7), 1387-1405.

Arouri, M. E. H., Jouini, J., Nguyen, D. K., 2012. On the Impacts of Oil Price Fluctuations on European Equity Markets: Volatility Spillover and Hedging Effectiveness. Energy Economics $34(2), 611-617$.

Arouri, M. E. H., Lahiani, A., Nguyen, D. K., 2011b. Return and Volatility Transmission between World Oil Prices and Stock Markets of the GCC Countries. Economic Modelling 28 (4), 18151825 .

Awartani, B., Maghyereh, A. I., 2013. Dynamic Spillovers between Oil and Stock Markets in the Gulf Cooperation Council Countries. Energy Economics 36 (C), 28-42.

Balcılar, M., Demirer, R., Hammoudeh, S., Nguyen, D. K., 2016. Risk spillovers across the energy and carbon markets and hedging strategies for carbon risk. Energy Economics 54, $159-172$.

Boldanov, R., Degiannakis, S., Filis, G., 2016. Time-varying correlation between oil and stock market volatilities: Evidence from oil-importing and oil-exporting countries. International Review of Financial Analysis 48, 209-220.

Boyer, M. M., Filion, D., 2007. Common and Fundamental Factors in Stock Returns of Canadian Oil and Gas Companies. Energy Economics 29 (3), 428-453.

BP, February 2 2016. BP reports full year and 4Q 2015 results; dividend remains unchanged. URL http://www.bp.com/en/global/corporate/press/press-releases/ fourth-quarter-2015-results.html

Broadstock, D. C., Cao, H., Zhang, D., 2012. Oil shocks and their impact on energy related stocks in china. Energy Economics 34 (6), 1888-1895.

Broadstock, D. C., Filis, G., 2014. Oil Price Shocks and Stock Market Returns: New Evidence from the United States and China. Journal of International Financial Markets, Institutions and Money $33(\mathrm{C})$, 417-433. 
Caporale, G. M., Menla Ali, F., Spagnolo, N., 2015. Oil Price Uncertainty and Sectoral Stock Returns in China: A Time-Varying Approach. China Economic Review 34 (C), 311-321.

Chang, C.-L., McAleer, M., Tansuchat, R., Aug. 2009. Volatility Spillovers Between Crude Oil Futures Returns and Oil Company Stocks Return. CARF F-Series CARF-F-157, Center for Advanced Research in Finance, Faculty of Economics, The University of Tokyo.

Chang, C.-L., McAleer, M., Tansuchat, R., 2011. Crude oil hedging strategies using dynamic multivariate garch. Energy Economics 33 (5), 912-923.

Chang, C.-L., McAleer, M., Tansuchat, R., 2013. Conditional Correlations and Volatility Spillovers between Crude Oil and Stock Index Returns. The North American Journal of Economics and Finance 25 (C), 116-138.

Choi, K., Hammoudeh, S., 2010. Volatility behavior of oil, industrial commodity and stock markets in a regime-switching environment. Energy Policy 38 (8), 4388-4399.

Cunado, J., Perez de Gracia, F., 2014. Oil Price Shocks and Stock Market Returns: Evidence for Some European Countries. Energy Economics 42 (C), 365-377.

Degiannakis, S., Filis, G., Floros, C., 2013. Oil and Stock Returns: Evidence from European Industrial Sector Indices in a Time-Varying Environment. Journal of International Financial Markets, Institutions and Money 26 (C), 175-191.

Degiannakis, S., Filis, G., Kizys, R., 2014. The Effects of Oil Price Shocks on Stock Market Volatility: Evidence from European Data. The Energy Journal 35 (1), 3556.

Diebold, F. X., Yilmaz, K., 2009. Measuring Financial Asset Return and Volatility Spillovers, with Application to Global Equity Markets. Economic Journal 119 (534), 158-171.

Diebold, F. X., Yilmaz, K., 2012. Better to Give than to Receive: Predictive Directional Measurement of Volatility Spillovers. International Journal of Forecasting 28 (1), 57-66.

Diebold, F. X., Yilmaz, K., 2014. On the Network Topology of Variance Decompositions: Measuring the Connectedness of Financial Firms. Journal of Econometrics 182 (1), 119-134.

Diebold, F. X., Yilmaz, K., 2015. Financial and Macroeconomic Connectedness: A Network Approach to Measurement and Monitoring. Oxford University Press.

Elyasiani, E., Mansur, I., Odusami, B., 2011. Oil Price Shocks and Industry Stock Returns. Energy Economics 33 (5), 966-974.

Engle, R., 2002. Dynamic Conditional Correlation: A Simple Class of Multivariate Generalized Autoregressive Conditional Heteroskedasticity Models. Journal of Business 83 Economic Statistics 20 (3), 339-50. 
Engle, R., Kroner, K., 1995. Multivariate Simultaneous Generalized ARCH. Econometric Theory $11(1), 122-150$.

Ewing, B. T., Malik, F., 2016. Volatility Spillovers between Oil Prices and the Stock Market under Structural Breaks. Global Finance Journal 29, 12-23.

Fantazzini, D., 2016. The Oil Price Crash in 2014/15: Was There a (Negative) Financial Bubble? Energy Policy 96, 383-396.

Filis, G., 2014. Time-varying co-movements between stock market returns and oil price shocks. International Journal of Energy and Statistics 2 (01), 27-42.

Filis, G., Degiannakis, S., Floros, C., 2011. Dynamic correlation between stock market and oil prices: The case of oil-importing and oil-exporting countries. International Review of Financial Analysis 20 (3), 152-164.

Fiorentini, G., Sentana, G., G., C., 2003. Maximum Likelihood Estimation and Inference in Multivariate Conditionally Heteroskedastic Dynamic Regression Models with Student t Innovations. Journal of Business and Economic Statistics 21, 532-546.

Forsberg, L., Ghysels, E., 2007. Why Do Absolute Returns Predict Volatility So Well? Journal of Financial Econometrics 5 (1), 31-67.

Giovannini, M., Grasso, M., Lanza, A., Manera, M., 2006. Conditional Correlations in the Returns on Oil Companies Stock Prices and their Determinants. Empirica 33 (4), 193-207.

Hammoudeh, S., Dibooglu, S., Aleisa, E., 2004. Relationships among U.S. Oil Prices and Oil Industry Equity Indices. International Review of Economics $\&$ Finance 13 (4), 427-453.

Hammoudeh, S., Li, H., 2005. Oil Sensitivity and Systematic Risk in Oil-Sensitive Stock Indices. Journal of Economics and Business 57 (1), 1-21.

Hammoudeh, S. M., Yuan, Y., McAleer, M., Thompson, M. A., 2010. Precious metals-exchange rate volatility transmissions and hedging strategies. International Review of Economics 83 Finance 19 (4), 633-647.

Harvey, A., Ruiz, E., N., S., 1992. Unobservable Component Time Series Models with ARCH Disturbances. Journal of Econometrics 52, 129-158.

Husain, A. M., Arezki, R., Breuer, P., Haksar, V., Helbling, T., Medas, P., Sommer, M., 2015. Global Implications of Lower Oil Prices. International Monetary Fund.

IMF, 2015. Spillover Report. International Monetary Fund.

Jones, C. M., Kaul, G., 1996. Oil and the stock markets. The Journal of Finance 51 (2), 463-491. Khalfaoui, R., Boutahar, M., Boubaker, H., 2015. Analyzing Volatility Spillovers and Hedging 
between Oil and Stock Markets: Evidence from Wavelet Analysis. Energy Economics 49 (C), $540-549$.

Kling, J. L., 1985. Oil Price Shocks and Stock Market Behavior. Journal of Portfolio Management 12,3439 .

Koop, G., Pesaran, M. H., Potter, S. M., 1996. Impulse Response Analysis in Nonlinear Multivariate Models. Journal of Econometrics 74 (1), 119-147.

Kroner, K. F., Ng, V. K., 1998. Modeling Asymmetric Movements of Asset Prices. Review of Financial Studies 11 (04), 817-844.

Kroner, K. F., Sultan, J., 1993. Time-Varying Distributions and Dynamic Hedging with Foreign Currency Futures. Journal of Financial and Quantitative Analysis 28 (04), 535-551.

Lanza, A., Manera, M., Grasso, M., Giovannini, M., 2005. Long-Run Models of Oil Stock Prices. Environmental Modelling $\&$ Software 20 (11), 1423-1430.

Ling, S., McAleer, M., 2003. Asymptotic Theory For A Vector Arma-Garch Model. Econometric Theory 19 (02), 280-310.

Maghyereh, A. I., Awartani, B., Bouri, E., 2016. The Directional Volatility Connectedness between Crude Oil and Equity Markets: New Evidence from Implied Volatility Indexes. Energy Economics 57, 78-93.

Maghyereh, A. I., Awartani, B., Tziogkidis, P., 2017. Volatility spillovers and cross-hedging between gold, oil and equities: Evidence from the gulf cooperation council countries. Energy Economics.

Malik, F., Ewing, B. T., 2009. Volatility Transmission between Oil Prices and Equity Sector Returns. International Review of Financial Analysis 18 (3), 95-100.

Malik, F., Hammoudeh, S., 2007. Shock and Volatility Transmission in the Oil, US and Gulf Equity Markets. International Review of Economics \& Finance 16 (3), 357-368.

Narayan, P. K., Sharma, S. S., 2011. New evidence on oil price and firm returns. Journal of Banking E Finance 35 (12), 3253-3262.

Park, J., Ratti, R. A., 2008. Oil Price Shocks and Stock Markets in the U.S. and 13 European Countries. Energy Economics 30 (5), 2587-2608.

Pesaran, H. H., Shin, Y., 1998. Generalized Impulse Response Analysis in Linear Multivariate Models. Economics Letters 58 (1), 17-29.

Phan, D. H. B., Sharma, S. S., Narayan, P. K., 2016. Intraday Volatility Interaction between the Crude Oil and Equity Markets. Journal of International Financial Markets, Institutions 
and Money $40(\mathrm{C}), 1-13$.

Sadorsky, P., 1999. Oil Price Shocks and Stock Market Activity. Energy Economics 21 (5), 449-469.

Sadorsky, P., 2001. Risk Factors in Stock Returns of Canadian Oil and Gas Companies. Energy Economics 23 (1), 17-28.

Sadorsky, P., 2008. The oil price exposure of global oil companies. Applied Financial Economics Letters 4 (2), 93-96.

Sadorsky, P., 2012. Correlations and Volatility Spillovers between Oil Prices and the Stock Prices of Clean Energy and Rechnology Companies. Energy Economics 34 (1), 248-255.

Scholtens, B., Yurtsever, C., 2012. Oil Price Shocks and European Industries. Energy Economics 34 (4), 1187-1195.

Sims, C., 1980. Macroeconomics and Reality. Econometrica 48, 1-48.

The Economist, February 6 2016. Oil Companies: In the Dark Ages.

URL http://tinyurl.com/zu8nrlm

Wall Street Journal, February 2 2016. Stocks Fall as Sliding Oil Prices Hit Energy Shares. URL http://tinyurl.com/h9ovuvl

Wang, G.-J., Xie, C., Jiang, Z.-Q., Stanley, H. E., 2016. Who are the Net Senders and Recipients of Volatility Spillovers in China's Financial Markets? Finance Research Letters. 
Table 1: Descriptive statistics of oil and stock price volatility (absolute returns)

\begin{tabular}{lcccccccccc}
\hline \hline & Mean & Median & Max & Min & Std. Dev. & Skewness & Kurtosis & Jarque-Bera & ADF & Obs. \\
WTI & 1.683 & 1.232 & 17.092 & 0.000 & 1.717 & 2.510 & 13.418 & $21250.8^{*}$ & $-8.146^{*}$ & 3814 \\
BP & 1.186 & 0.813 & 17.192 & 0.000 & 1.338 & 3.644 & 27.488 & $103736.8^{*}$ & $-11.354^{*}$ & 3814 \\
CHEVRON & 1.109 & 0.818 & 18.941 & 0.000 & 1.177 & 3.829 & 34.351 & $165519.3^{*}$ & $-9.847^{*}$ & 3814 \\
CNPC & 1.700 & 1.157 & 18.698 & 0.000 & 1.874 & 2.789 & 15.537 & $29921.4^{*}$ & $-10.372^{*}$ & 3814 \\
ENI & 1.289 & 0.920 & 13.913 & 0.000 & 1.353 & 2.676 & 14.773 & $26577.9^{*}$ & $-8.430^{*}$ & 3814 \\
EXXON & 1.038 & 0.751 & 15.863 & 0.000 & 1.130 & 3.791 & 31.560 & $138757.3^{*}$ & $-10.439^{*}$ & 3814 \\
LUKOIL & 1.791 & 1.221 & 39.502 & 0.000 & 2.099 & 4.416 & 46.211 & $309121.1^{*}$ & $-6.380^{*}$ & 3814 \\
PETROBRAS & 2.169 & 1.591 & 23.679 & 0.000 & 2.227 & 2.656 & 15.305 & $28543.9^{*}$ & $-9.665^{*}$ & 3814 \\
SHELL & 1.150 & 0.829 & 15.721 & 0.000 & 1.257 & 3.296 & 22.745 & $68858.5^{*}$ & $-7.709^{*}$ & 3814 \\
SINOPEC & 2.170 & 1.512 & 19.190 & 0.000 & 2.271 & 2.276 & 10.724 & $12774.8^{*}$ & $-14.552^{*}$ & 3814 \\
STATOIL & 1.560 & 1.176 & 16.128 & 0.000 & 1.574 & 2.558 & 14.659 & $25760.0^{*}$ & $-6.988^{*}$ & 3814 \\
TOTAL & 1.236 & 0.874 & 13.641 & 0.000 & 1.278 & 2.728 & 16.109 & $32037.5^{*}$ & $-6.361^{*}$ & 3814 \\
VALERO & 1.807 & 1.350 & 22.314 & 0.000 & 1.811 & 2.845 & 18.614 & $43890.0^{*}$ & $-6.918^{*}$ & 3814 \\
\hline \hline
\end{tabular}

Notes: * denotes significance at the $1 \%$ level. 
Table 2: Volatility spillovers table from variable $(j)$ to variable $(i)$

\begin{tabular}{|c|c|c|c|c|c|c|c|c|c|c|c|c|c|c|}
\hline \multirow[b]{2}{*}{ To (i) } & \multicolumn{14}{|c|}{ From $(j)$} \\
\hline & WTI & $\mathrm{BP}$ & CHEVRON & $\mathrm{CNPC}$ & ENI & EXXON & LUKOIL & PETROBRAS & SHELL & SINOPEC & STATOIL & TOTAL & VALERO & From Others \\
\hline WTI & 49.5 & 4.24 & 5.31 & 2.06 & 4.71 & 3.67 & 6.18 & 3.16 & 5.82 & 1.20 & 5.83 & 5.26 & 3.07 & 50.50 \\
\hline $\mathrm{BP}$ & 1.74 & 24.42 & 9.55 & 2.45 & 8.38 & 9.54 & 3.93 & 4.19 & 11.83 & 1.33 & 6.78 & 11.13 & 4.73 & 75.58 \\
\hline CHEVRON & 2.03 & 8.36 & 21.46 & 3.24 & 7.35 & 13.52 & 4.52 & 5.21 & 10.25 & 1.76 & 7.11 & 9.46 & 5.73 & 78.54 \\
\hline $\mathrm{CNPC}$ & 1.82 & 4.27 & 6.62 & 38.07 & 4.68 & 5.64 & 5.19 & 5.35 & 5.36 & 8.89 & 5.33 & 5.18 & 3.62 & 61.93 \\
\hline ENI & 1.95 & 8.40 & 8.39 & 2.62 & 23.09 & 7.58 & 4.72 & 4.51 & 11.27 & 1.71 & 7.44 & 14.03 & 4.29 & 76.91 \\
\hline EXXON & 1.44 & 8.87 & 14.6 & 3.19 & 7.20 & 22.95 & 3.79 & 4.74 & 10.33 & 1.52 & 6.23 & 9.53 & 5.60 & 77.05 \\
\hline LUKOIL & 3.16 & 5.63 & 6.87 & 3.92 & 6.39 & 5.28 & 32.76 & 5.66 & 7.29 & 2.25 & 8.48 & 7.73 & 4.57 & 67.24 \\
\hline PETROBRAS & 1.84 & 5.66 & 8.27 & 4.15 & 5.97 & 6.90 & 5.87 & 32.06 & 7.34 & 2.56 & 7.17 & 7.88 & 4.33 & 67.94 \\
\hline SHELL & 2.08 & 10.03 & 10.14 & 2.54 & 9.82 & 9.39 & 4.39 & 4.69 & 21.16 & 1.52 & 6.94 & 12.87 & 4.45 & 78.84 \\
\hline SINOPEC & 1.64 & 2.90 & 4.84 & 11.41 & 3.97 & 3.71 & 3.45 & 4.12 & 4.13 & 48.25 & 4.17 & 4.43 & 2.98 & 51.75 \\
\hline STATOIL & 2.87 & 7.27 & 8.7 & 3.32 & 7.89 & 6.95 & 6.77 & 5.84 & 8.77 & 1.95 & 24.81 & 9.71 & 5.15 & 75.19 \\
\hline TOTAL & 1.78 & 9.44 & 9.25 & 2.59 & 11.94 & 8.48 & 4.68 & 4.83 & 12.66 & 1.79 & 7.65 & 20.24 & 4.68 & 79.76 \\
\hline VALERO & 2.04 & 6.55 & 8.92 & 3.01 & 5.90 & 7.97 & 4.91 & 4.53 & 6.99 & 1.88 & 6.29 & 7.43 & 33.59 & 66.41 \\
\hline Contr. to others & 24.38 & 81.63 & 101.44 & 44.48 & 84.20 & 88.61 & 58.41 & 56.83 & 102.05 & 28.37 & 79.41 & 104.65 & 53.20 & Total spillover \\
\hline Contr. incl. own & 73.89 & 106.05 & 122.90 & 82.55 & 107.29 & 111.56 & 91.17 & 88.89 & 123.20 & 76.61 & 104.22 & 124.88 & 86.79 & index $=69.82 \%$ \\
\hline Net spillovers & -26.12 & 6.05 & 22.90 & -17.45 & 7.29 & 11.56 & -8.83 & -11.11 & 23.21 & -23.38 & 4.22 & 24.89 & -13.21 & \\
\hline
\end{tabular}

Notes: Values reported are variance decompositions of the estimated VAR model for the volatilities (i.e., absolute returns) of the series. Variance decompositions are based on 30-days-ahead forecasts. A VAR lag length of order 1 was selected by the Schwarz Bayesian information criterion. 
Table 3: Hedge ratios and portfolio weights: summary statistics

\begin{tabular}{|c|c|c|c|c|c|c|c|c|c|c|c|c|c|c|c|c|}
\hline & \multicolumn{4}{|c|}{$\begin{array}{c}\text { Full Sample } \\
(19.06 .2001-01.02 .2016)\end{array}$} & \multicolumn{4}{|c|}{$\begin{array}{c}\text { Pre-Financial Crisis } \\
\text { (19.06.2001-30.11.2007) }\end{array}$} & \multicolumn{4}{|c|}{$\begin{array}{c}\text { Financial Crisis } \\
\text { (03.12.2007-01.06.2009) }\end{array}$} & \multicolumn{4}{|c|}{$\begin{array}{c}\text { Post-Financial Crisis } \\
\text { (02.06.2009-01.02.2016) }\end{array}$} \\
\hline \multicolumn{17}{|c|}{ Panel A: Hedge ratios (long/short) } \\
\hline & Mean & St. Dev. & Min & Max & Mean & St. Dev. & Min & Max & Mean & St. Dev. & Min & Max & Mean & St. Dev. & Min & $\operatorname{Max}$ \\
\hline WTI/BP & 0.19 & 0.09 & 0.04 & 0.65 & 0.14 & 0.07 & 0.04 & 0.52 & 0.22 & 0.10 & 0.12 & 0.64 & 0.23 & 0.08 & 0.10 & 0.65 \\
\hline WTI/CHEVRON & 0.17 & 0.07 & 0.04 & 0.58 & 0.13 & 0.05 & 0.04 & 0.40 & 0.20 & 0.10 & 0.11 & 0.58 & 0.21 & 0.06 & 0.09 & 0.54 \\
\hline WTI/CNPC & 0.19 & 0.08 & 0.04 & 0.60 & 0.16 & 0.07 & 0.04 & 0.47 & 0.25 & 0.10 & 0.13 & 0.60 & 0.20 & 0.07 & 0.04 & 0.53 \\
\hline WTI/ENI & 0.17 & 0.10 & 0.02 & 0.65 & 0.10 & 0.03 & 0.02 & 0.22 & 0.21 & 0.10 & 0.10 & 0.51 & 0.23 & 0.09 & 0.10 & 0.65 \\
\hline WTI/EXXON & 0.14 & 0.06 & 0.03 & 0.54 & 0.11 & 0.06 & 0.03 & 0.46 & 0.16 & 0.09 & 0.08 & 0.54 & 0.17 & 0.05 & 0.07 & 0.48 \\
\hline WTI/LUKOIL & 0.29 & 0.12 & 0.05 & 0.87 & 0.22 & 0.09 & 0.05 & 0.67 & 0.35 & 0.17 & 0.17 & 0.87 & 0.34 & 0.10 & 0.14 & 0.77 \\
\hline WTI/PETROBRAS & 0.25 & 0.12 & 0.04 & 0.80 & 0.18 & 0.07 & 0.04 & 0.45 & 0.31 & 0.15 & 0.16 & 0.76 & 0.32 & 0.10 & 0.12 & 0.80 \\
\hline WTI/SHELL & 0.18 & 0.08 & 0.03 & 0.57 & 0.13 & 0.06 & 0.03 & 0.48 & 0.21 & 0.10 & 0.10 & 0.55 & 0.21 & 0.06 & 0.10 & 0.57 \\
\hline WTI/SINOPEC & 0.20 & 0.09 & 0.02 & 0.61 & 0.16 & 0.07 & 0.02 & 0.50 & 0.25 & 0.07 & 0.12 & 0.46 & 0.22 & 0.09 & 0.03 & 0.61 \\
\hline WTI/STATOIL & 0.27 & 0.10 & 0.07 & 0.70 & 0.19 & 0.07 & 0.07 & 0.39 & 0.32 & 0.10 & 0.19 & 0.62 & 0.33 & 0.08 & 0.15 & 0.70 \\
\hline WTI/TOTAL & 0.17 & 0.08 & 0.03 & 0.55 & 0.12 & 0.05 & 0.03 & 0.34 & 0.19 & 0.09 & 0.08 & 0.47 & 0.22 & 0.07 & 0.12 & 0.55 \\
\hline WTI/VALERO & 0.24 & 0.11 & 0.04 & 0.74 & 0.21 & 0.08 & 0.04 & 0.46 & 0.28 & 0.08 & 0.16 & 0.52 & 0.27 & 0.12 & 0.06 & 0.74 \\
\hline $\mathrm{BP} / \mathrm{WTI}$ & 0.38 & 0.14 & 0.06 & 0.98 & 0.36 & 0.12 & 0.09 & 0.81 & 0.45 & 0.21 & 0.16 & 0.98 & 0.38 & 0.14 & 0.06 & 0.95 \\
\hline CHEVRON/WTI & 0.45 & 0.17 & 0.11 & 1.13 & 0.38 & 0.16 & 0.11 & 1.03 & 0.46 & 0.25 & 0.17 & 1.13 & 0.50 & 0.14 & 0.19 & 1.07 \\
\hline CNPC/WTI & 0.18 & 0.09 & 0.01 & 0.57 & 0.15 & 0.10 & 0.01 & 0.57 & 0.20 & 0.14 & 0.03 & 0.57 & 0.20 & 0.06 & 0.05 & 0.44 \\
\hline LUKOIL/WTI & 0.25 & 0.08 & 0.06 & 0.60 & 0.21 & 0.06 & 0.08 & 0.44 & 0.22 & 0.10 & 0.06 & 0.46 & 0.29 & 0.07 & 0.13 & 0.60 \\
\hline PETROBRAS/WTI & 0.17 & 0.09 & 0.01 & 0.58 & 0.15 & 0.07 & 0.01 & 0.45 & 0.23 & 0.15 & 0.03 & 0.58 & 0.18 & 0.08 & 0.01 & 0.43 \\
\hline SHELL/WTI & 0.38 & 0.14 & 0.06 & 0.88 & 0.33 & 0.13 & 0.06 & 0.88 & 0.41 & 0.17 & 0.15 & 0.84 & 0.43 & 0.13 & 0.17 & 0.85 \\
\hline SINOPEC/WTI & 0.10 & 0.06 & 0.01 & 0.50 & 0.08 & 0.04 & 0.01 & 0.26 & 0.19 & 0.12 & 0.04 & 0.50 & 0.11 & 0.04 & 0.01 & 0.25 \\
\hline STATOIL/WTI & 0.32 & 0.11 & 0.10 & 0.77 & 0.27 & 0.11 & 0.11 & 0.77 & 0.32 & 0.15 & 0.10 & 0.65 & 0.36 & 0.09 & 0.19 & 0.77 \\
\hline TOTAL/WTI & 0.33 & 0.12 & 0.07 & 0.77 & 0.30 & 0.12 & 0.07 & 0.69 & 0.34 & 0.14 & 0.10 & 0.70 & 0.36 & 0.11 & 0.12 & 0.77 \\
\hline VALERO/WTI & 0.21 & 0.07 & 0.04 & 0.49 & 0.21 & 0.07 & 0.04 & 0.49 & 0.22 & 0.11 & 0.08 & 0.48 & 0.20 & 0.06 & 0.08 & 0.46 \\
\hline \multicolumn{17}{|c|}{ Panel B: Portfolio weights (WTI/Company $j$ ) } \\
\hline & Mean & St. Dev. & Min & Max & Mean & St. Dev. & Min & $\operatorname{Max}$ & Mean & St. Dev. & Min & Max & Mean & St. Dev. & Min & $\operatorname{Max}$ \\
\hline WTI/BP & 0.30 & 0.18 & 0.00 & 0.96 & 0.26 & 0.17 & 0.01 & 0.91 & 0.31 & 0.18 & 0.00 & 0.89 & 0.34 & 0.17 & 0.01 & 0.96 \\
\hline WTI/CHEVRON & 0.23 & 0.15 & 0.00 & 0.86 & 0.22 & 0.15 & 0.00 & 0.84 & 0.30 & 0.19 & 0.00 & 0.86 & 0.22 & 0.12 & 0.00 & 0.75 \\
\hline WTI/CNPC & 0.52 & 0.18 & 0.07 & 0.98 & 0.52 & 0.20 & 0.07 & 0.98 & 0.64 & 0.21 & 0.10 & 0.97 & 0.50 & 0.15 & 0.09 & 0.88 \\
\hline WTI/ENI & 0.35 & 0.16 & 0.02 & 0.90 & 0.28 & 0.13 & 0.04 & 0.78 & 0.36 & 0.16 & 0.02 & 0.78 & 0.41 & 0.16 & 0.07 & 0.90 \\
\hline WTI/EXXON & 0.23 & 0.15 & 0.00 & 0.92 & 0.24 & 0.17 & 0.01 & 0.92 & 0.30 & 0.20 & 0.00 & 0.85 & 0.21 & 0.10 & 0.00 & 0.66 \\
\hline WTI/LUKOIL & 0.54 & 0.17 & 0.08 & 0.98 & 0.51 & 0.17 & 0.08 & 0.96 & 0.60 & 0.16 & 0.28 & 0.98 & 0.54 & 0.15 & 0.16 & 0.92 \\
\hline WTI/PETROBRAS & 0.61 & 0.19 & 0.10 & 0.98 & 0.55 & 0.19 & 0.10 & 0.98 & 0.64 & 0.22 & 0.12 & 0.98 & 0.67 & 0.14 & 0.22 & 0.96 \\
\hline WTI/SHELL & 0.27 & 0.15 & 0.01 & 0.93 & 0.25 & 0.16 & 0.01 & 0.93 & 0.32 & 0.17 & 0.03 & 0.85 & 0.28 & 0.12 & 0.03 & 0.76 \\
\hline WTI/SINOPEC & 0.67 & 0.16 & 0.12 & 0.96 & 0.65 & 0.16 & 0.18 & 0.96 & 0.68 & 0.20 & 0.12 & 0.95 & 0.70 & 0.13 & 0.20 & 0.96 \\
\hline
\end{tabular}


Table 4: Performance of optimal hedge ratio strategy for a volatility portfolio

\begin{tabular}{|c|c|c|c|c|}
\hline & \multirow[t]{2}{*}{ Average $\beta$} & \multicolumn{2}{|c|}{ Portfolios Variance } & \multirow[t]{2}{*}{$\operatorname{HE}^{1}(\%)$} \\
\hline & & Unhedged long position & Optimal & \\
\hline \multicolumn{5}{|c|}{ WTI volatility portfolio (long/short) } \\
\hline WTI/BP & 0.19 & 3.02 & 2.95 & 2.35 \\
\hline WTI/CHEVRON & 0.17 & 3.02 & 2.89 & 4.33 \\
\hline WTI/CNPC & 0.19 & 3.02 & 3.02 & 0.01 \\
\hline WTI/ENI & 0.17 & 3.02 & 2.88 & 4.64 \\
\hline WTI/EXXON & 0.14 & 3.02 & 2.94 & 2.67 \\
\hline WTI/LUKOIL & 0.29 & 3.02 & 3.50 & -16.05 \\
\hline WTI/PETROBRAS & 0.25 & 3.02 & 3.31 & -9.76 \\
\hline WTI/SHELL & 0.18 & 3.02 & 2.88 & 4.53 \\
\hline WTI/SINOPEC & 0.20 & 3.02 & 3.11 & -2.89 \\
\hline WTI/STATOIL & 0.27 & 3.02 & 2.78 & 7.79 \\
\hline WTI/TOTAL & 0.17 & 3.02 & 2.87 & 4.98 \\
\hline WTI/VALERO & 0.24 & 3.02 & 3.00 & 0.43 \\
\hline \multicolumn{5}{|c|}{ Company $j$ volatility portfolios (long/short) } \\
\hline $\mathrm{BP} / \mathrm{WTI}$ & 0.38 & 1.83 & 2.16 & -18.01 \\
\hline CHEVRON/WTI & 0.45 & 1.36 & 2.03 & -49.98 \\
\hline CNCPC/WTI & 0.18 & 3.53 & 3.49 & 1.07 \\
\hline ENI/WTI & 0.28 & 1.87 & 2.00 & -7.22 \\
\hline EXXON/WTI & 0.40 & 1.25 & 1.94 & -55.95 \\
\hline LUKOIL/WTI & 0.25 & 4.35 & 4.13 & 5.17 \\
\hline PETROBRAS/WTI & 0.17 & 5.18 & 5.01 & 3.15 \\
\hline SHELL/WTI & 0.38 & 1.58 & 1.89 & -19.14 \\
\hline SINOPEC/WTI & 0.10 & 5.24 & 5.17 & 1.29 \\
\hline STATOIL/WTI & 0.32 & 2.43 & 2.37 & 2.41 \\
\hline TOTAL/WTI & 0.33 & 1.68 & 1.86 & -10.48 \\
\hline VALERO/WTI & 0.21 & 3.28 & 3.17 & 3.43 \\
\hline
\end{tabular}

Notes:

(1) $\mathrm{HE}=$ Hedging Effectiveness

All values are average daily values. 
Table 5: Performance of an optimal portfolio weights strategy

\begin{tabular}{lcccc}
\hline \hline Portfolio & Portfolio weights & \multicolumn{2}{c}{ Portfolio Variance } & HE $^{1}(\%)$ \\
& WTI/Company $j$ & Optimal weighted port. & Unhedged long position & \\
\hline WTI, BP & 0.30 & 1.14 & $3.02,1.83$ & $62.20,37.56$ \\
WTI, CHEVRON & 0.23 & 0.98 & $3.02,1.36$ & $67.45,27.53$ \\
WTI, CNPC & 0.52 & 1.59 & $3.02,3.53$ & $47.27,54.85$ \\
WTI, ENI & 0.35 & 1.26 & $3.02,1.87$ & $58.14,32.39$ \\
WTI, EXXON & 0.23 & 0.88 & $3.02,1.25$ & $70.95,29.60$ \\
WTI, LUKOIL & 0.54 & 1.90 & $3.02,4.35$ & $36.93,56.25$ \\
WTI, PETROBRAS & 0.61 & 1.92 & $3.02,5.18$ & $36.45,62.92$ \\
WTI, SHELL & 0.27 & 1.11 & $3.02,1.58$ & $63.25,29.95$ \\
WTI, SINOPEC & 0.67 & 1.87 & $3.02,5.24$ & $37.84,64.20$ \\
WTI, STATOIL & 0.44 & 1.59 & $3.02,2.43$ & $47.21,34.47$ \\
WTI, TOTAL & 0.31 & 1.18 & $3.02,1.68$ & $60.79,29.81$ \\
WTI, VALERO & 0.53 & 1.68 & $3.02,3.28$ & $44.12,48.61$ \\
\hline
\end{tabular}

Notes:

(1) $\mathrm{HE}=$ Hedging Effectiveness.

All values are average daily values. In the last two columns of the table, the first value refers to the WTI and the second value to the company $j$. 
Figure 1: Oil and stock price volatility (absolute returns)
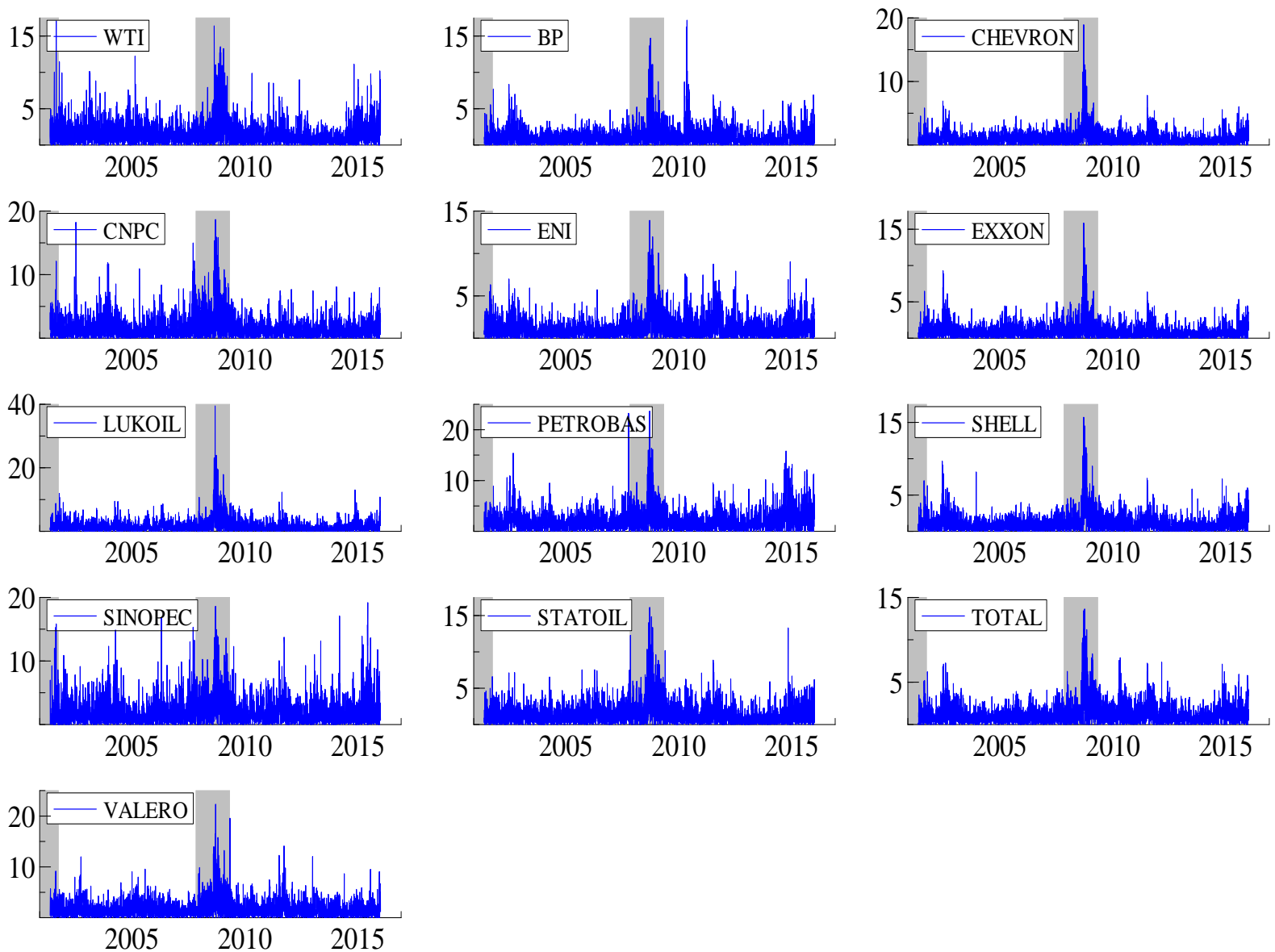

Note: Shading areas denote US recessions as defined by the National Bureau of Economic Research (NBER) business cycles dating committee. 
Figure 2: Dynamic conditional correlations between WTI volatility and oil companies' stock price volatility
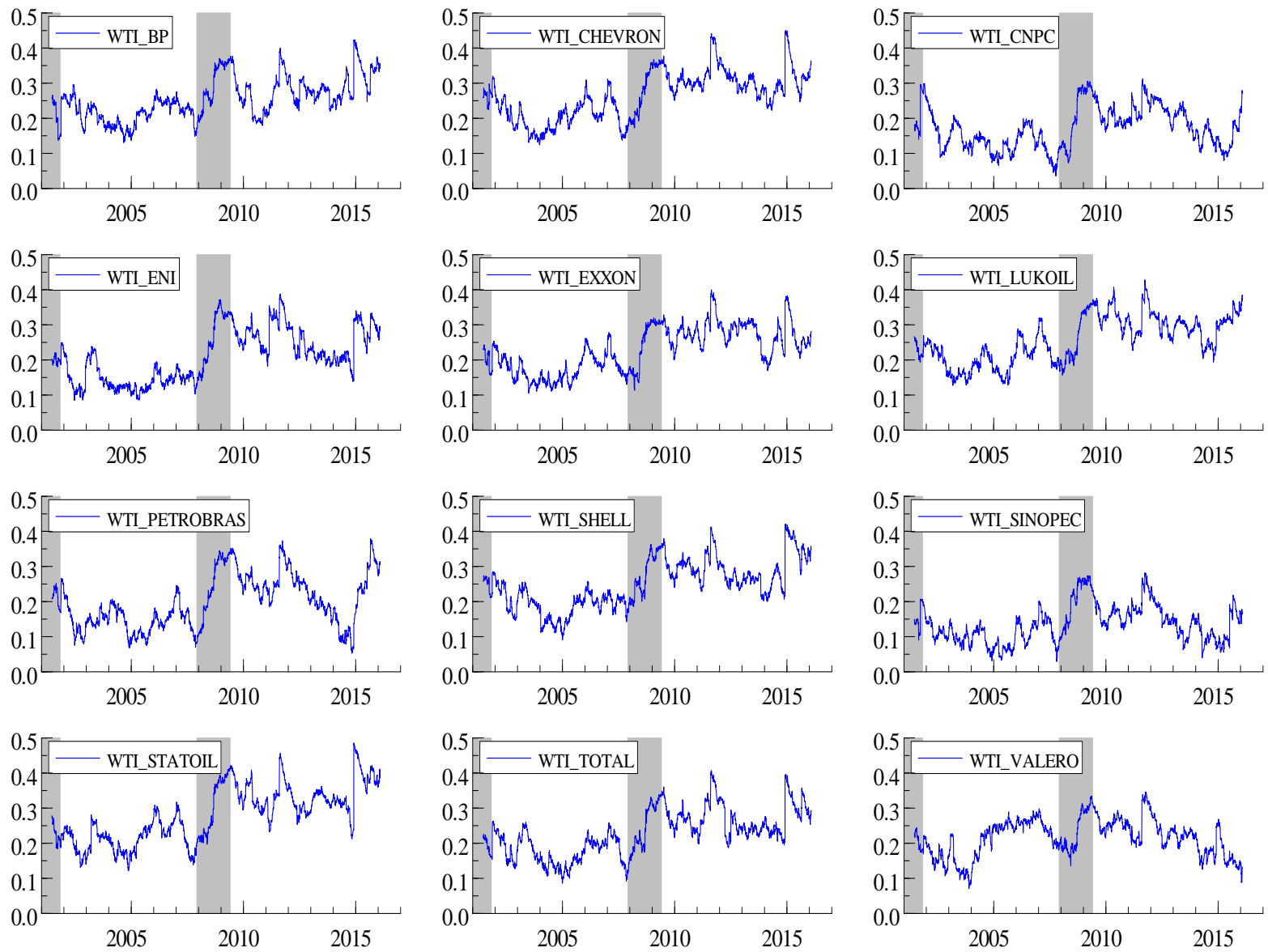

Note: Shading areas denote US recessions as defined by the National Bureau of Economic Research (NBER) business cycles dating committee. 
Figure 3: Total volatility spillover

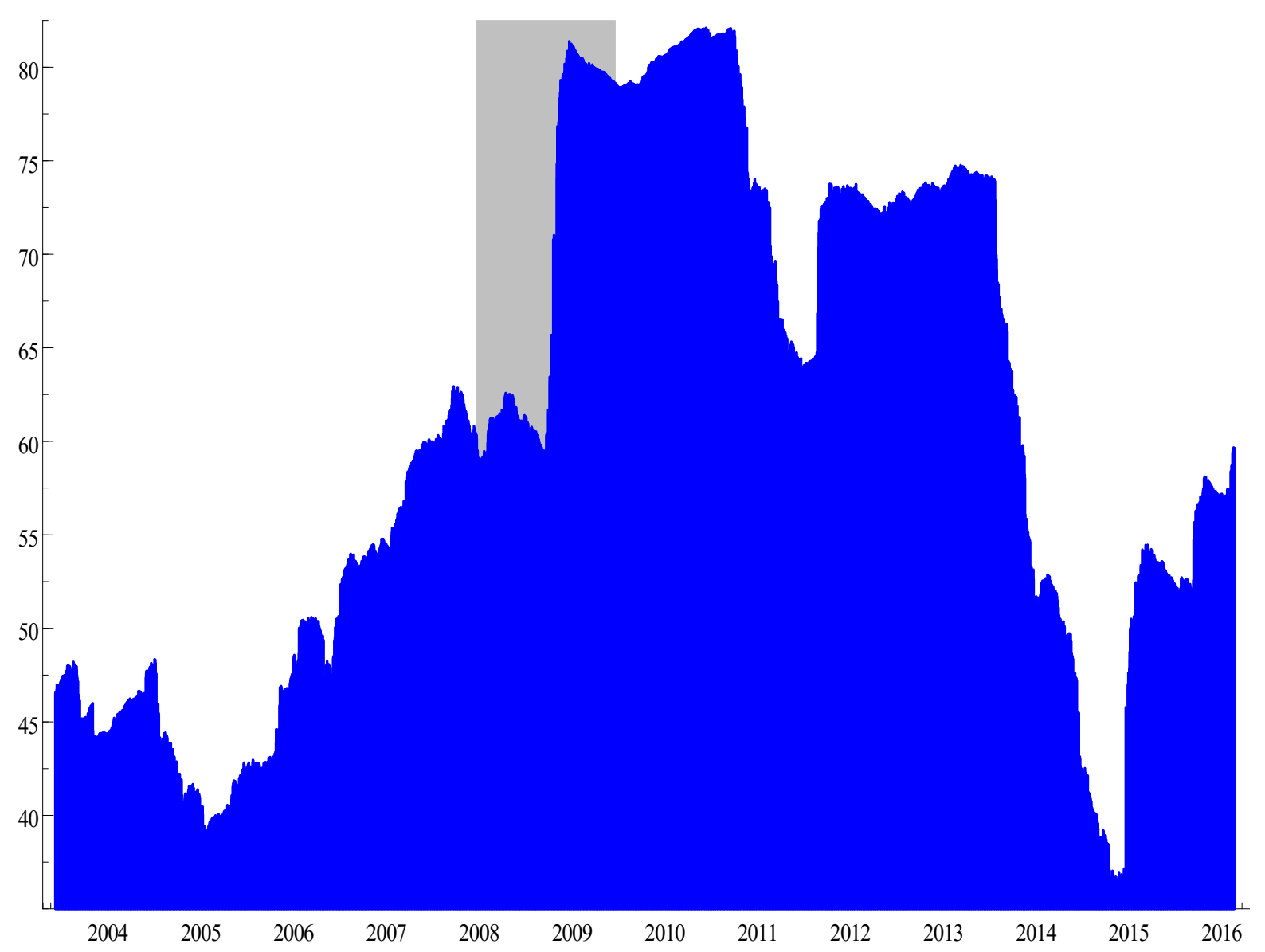

Note: Shading areas denote US recessions as defined by the National Bureau of Economic Research (NBER) business cycles dating committee. 
Figure 4: Net pairwise directional volatility spillovers
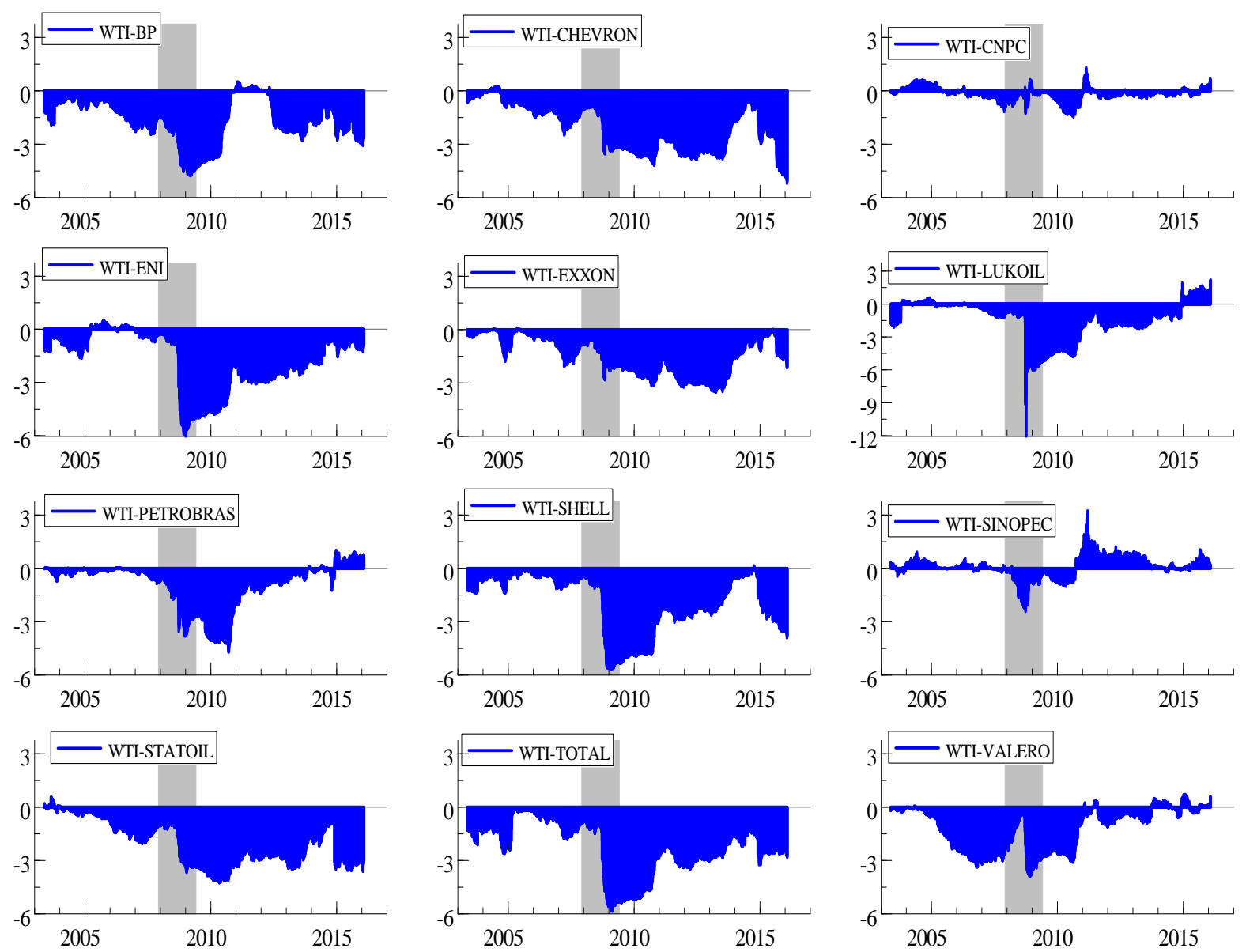

Note: Shading areas denote US recessions as defined by the National Bureau of Economic Research (NBER) business cycles dating committee. 
Figure 5: Dynamic hedge ratios (long/short)
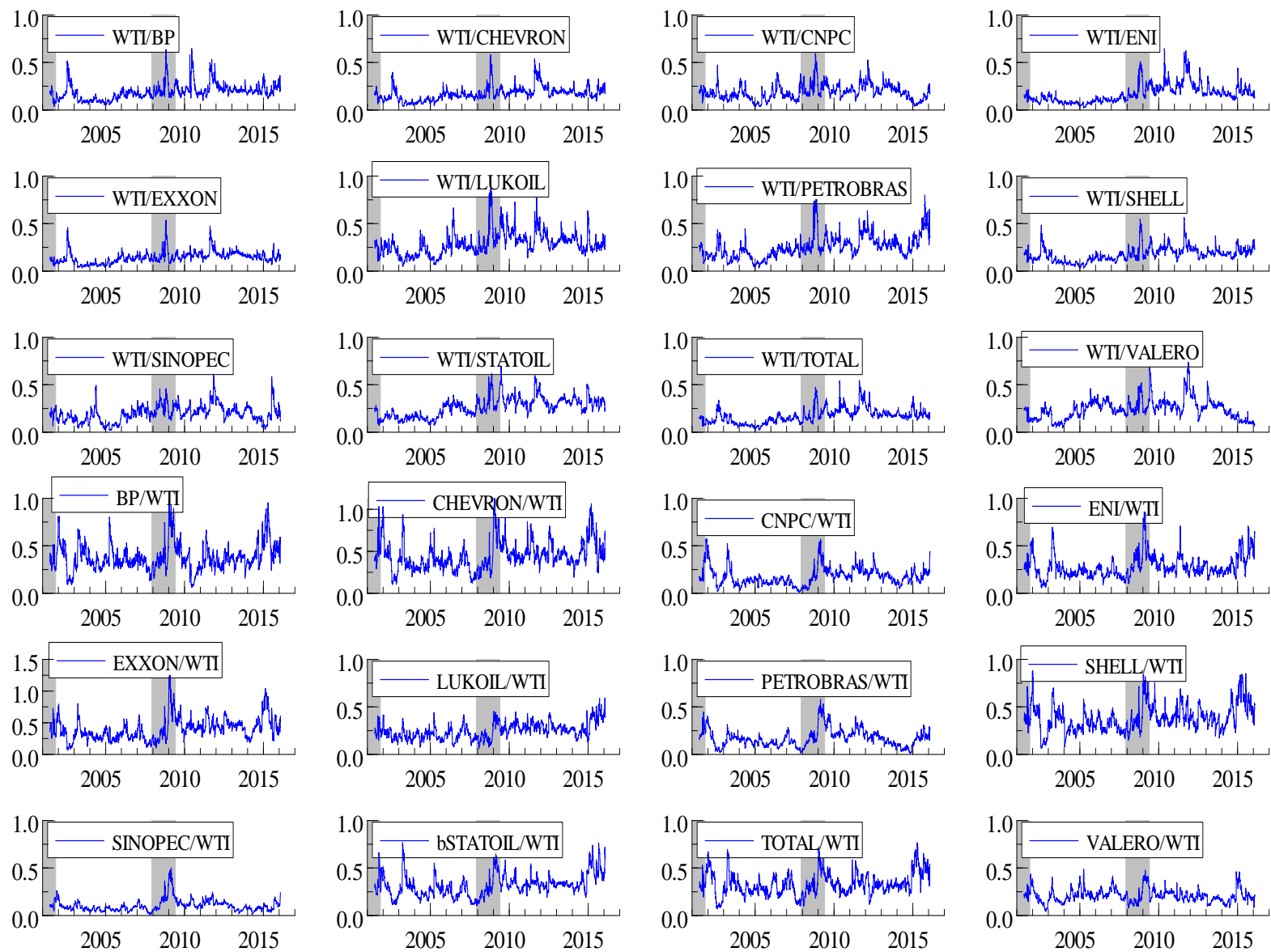

Note: Shading areas denote US recessions as defined by the National Bureau of Economic Research (NBER) business cycles dating committee. 
Figure 6: Dynamic portfolio weights
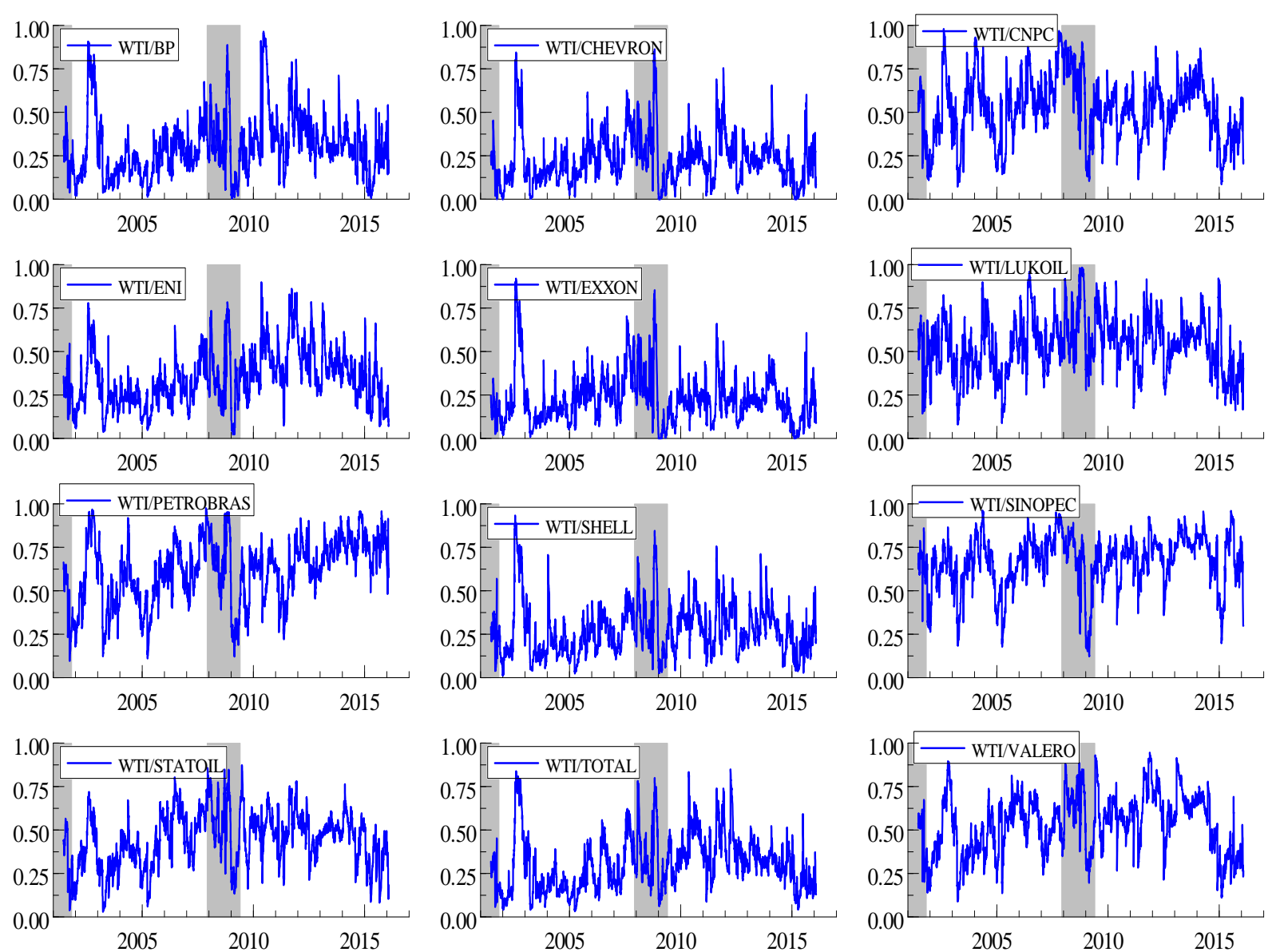

Note: Shading areas denote US recessions as defined by the National Bureau of Economic Research (NBER) business cycles dating committee. 


\section{Appendix}

Figure A.1: Directional volatility spillovers from each variable $i$ to all others
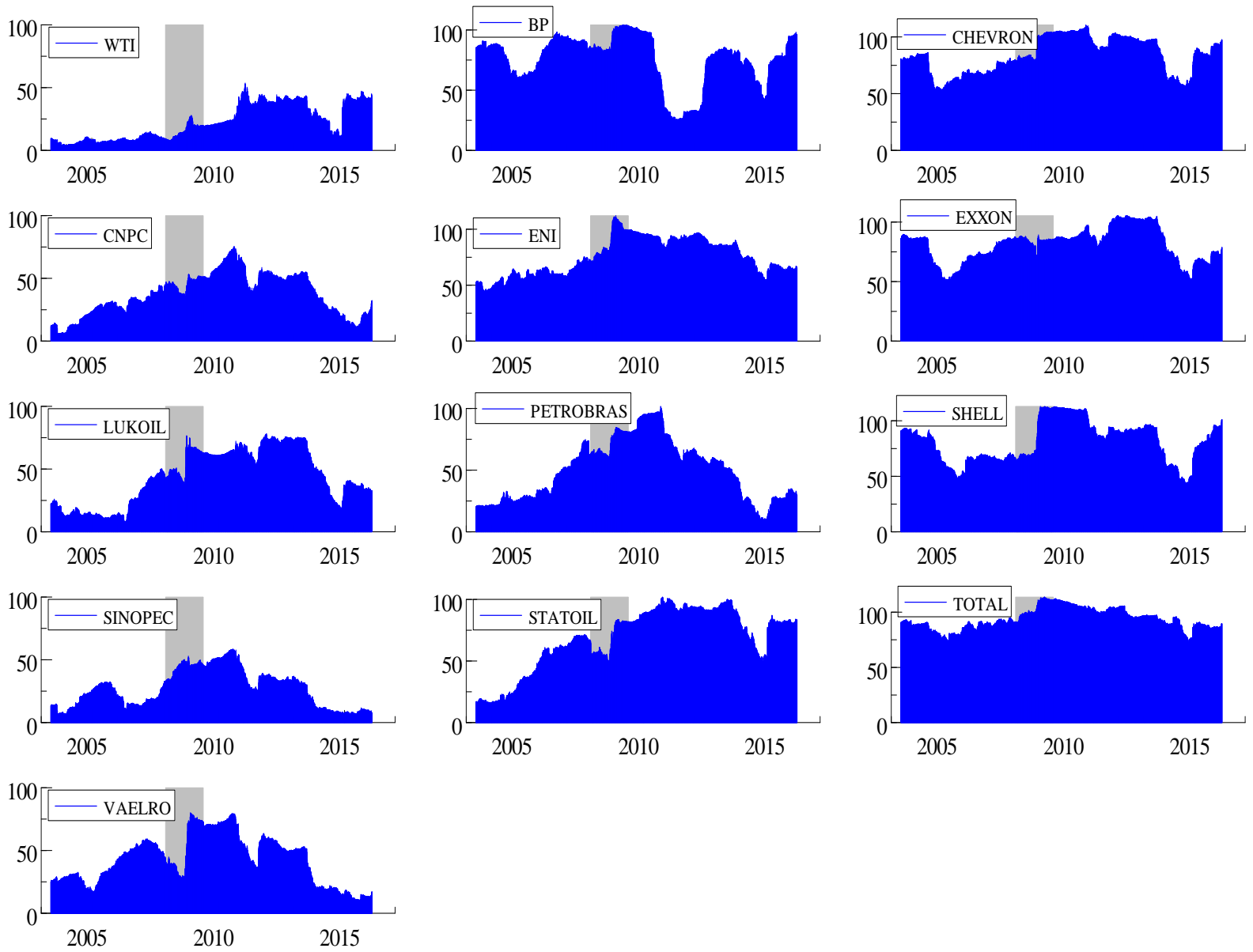

Note: Shading areas denote US recessions as defined by the National Bureau of Economic Research (NBER) business cycles dating committee. 
Figure A.2: Directional volatility spillovers to each variable $i$ from all others
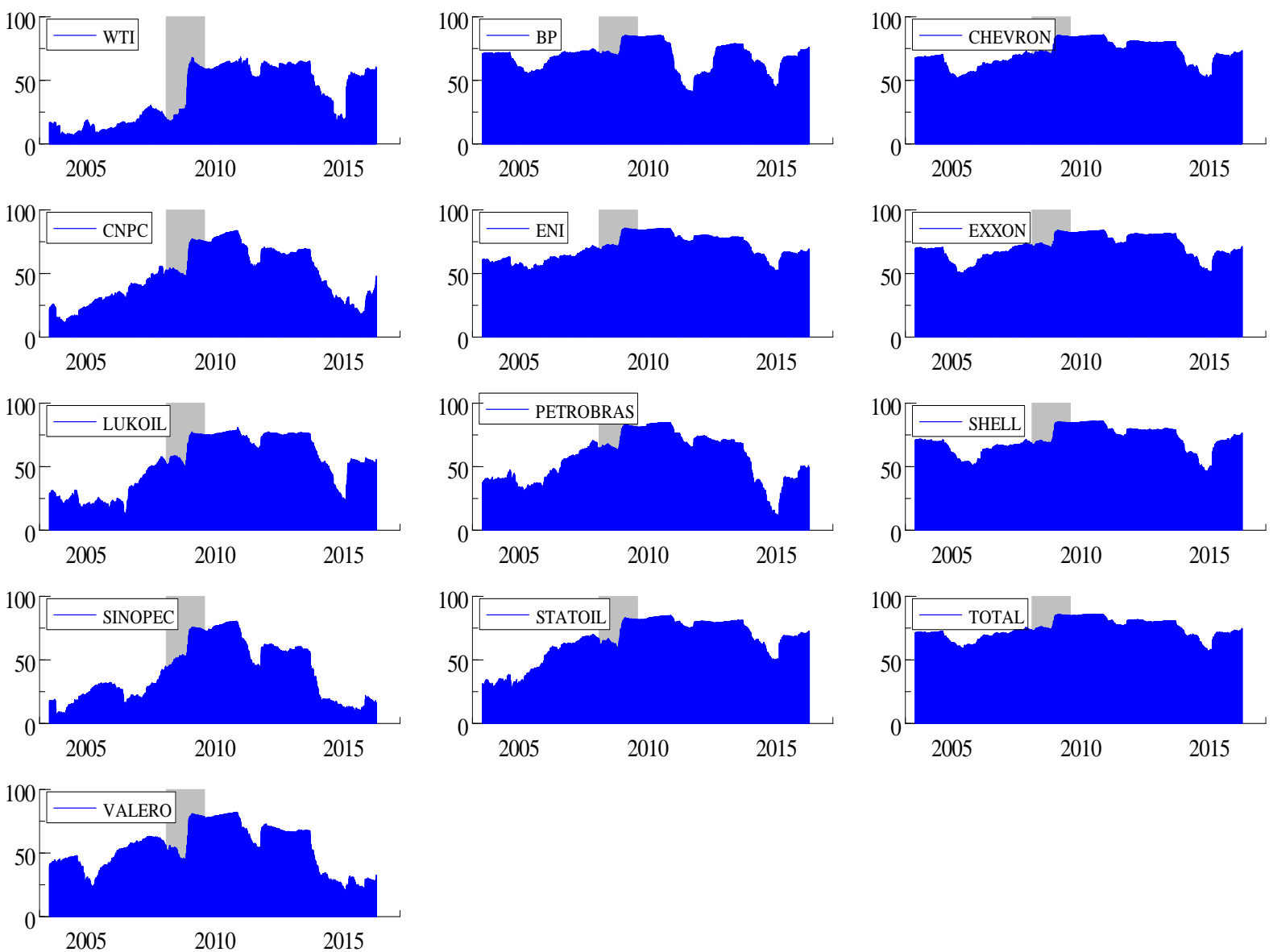

Note: Shading areas denote US recessions as defined by the National Bureau of Economic Research (NBER) business cycles dating committee. 
Figure A.3: Net directional volatility spillovers (from each variable to all others)
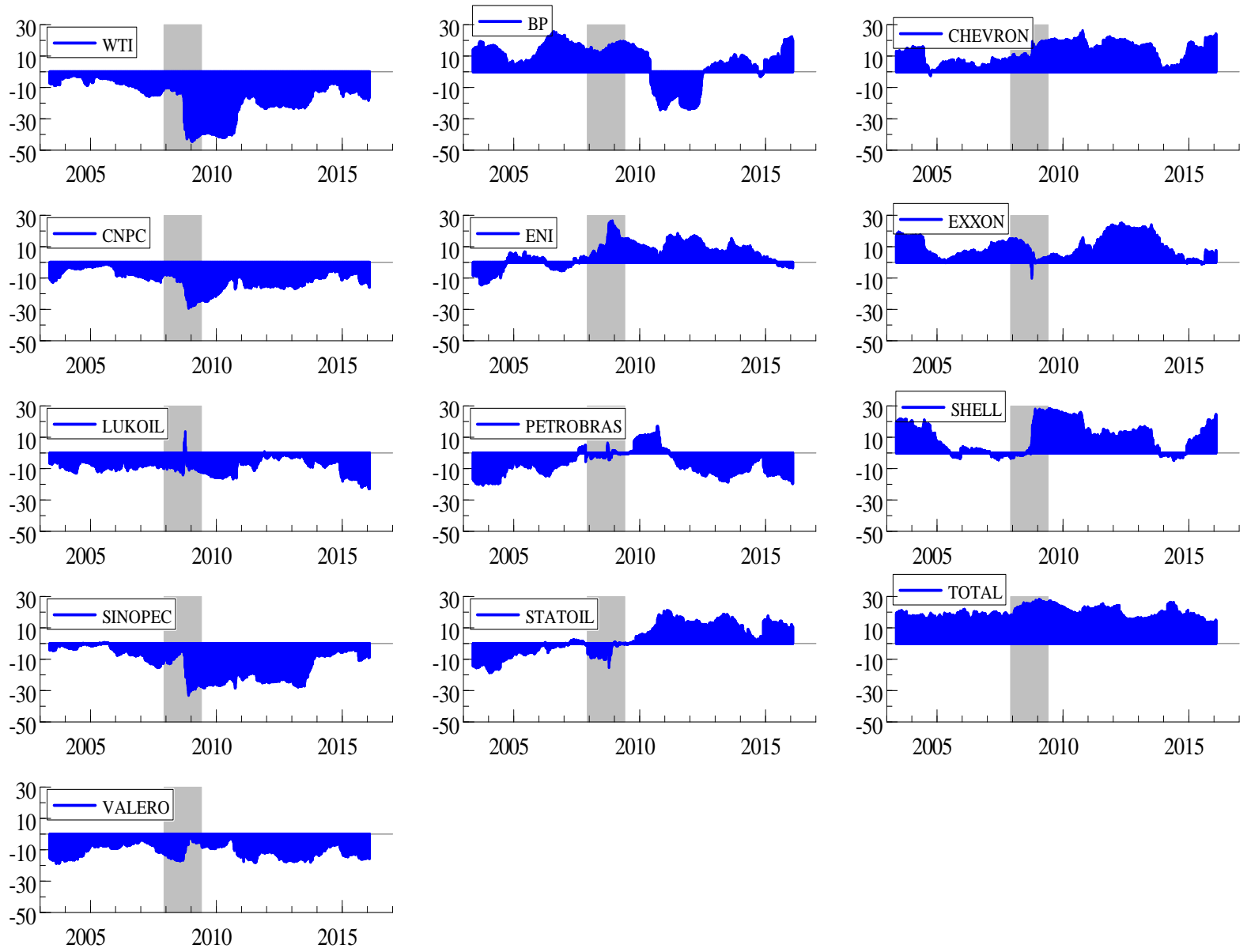

Note: Shading areas denote US recessions as defined by the National Bureau of Economic Research (NBER) business cycles dating committee. 